\title{
Hydromagnetic Boundary Layer Flow and Heat Transfer Characteristics of a Nanofluid over an Inclined Stretching Surface in the Presence of a Convective Surface: A Comprehensive Study
}

\author{
Mohammad M. Rahman* and Mohammed M. Al-Hatmi
}

Department of Mathematics and Statistics, College of Science, Sultan Qaboos University, PO Box 36, Al-Khod, PC 123, Muscat, Sultanate of Oman. *Email: mansur@squ.edu.om.

\begin{abstract}
In this paper we investigate numerically the hydromagnetic boundary layer flow and heat transfer characteristics of a nanofluid using three types of nanoparticles (copper, aluminium oxide and titanium dioxide) having various shapes (spherical, cylindrical, arbitrary, etc) by considering three kinds of base fluids (water, ethylene glycol and engine oil) over a nonlinear inclined stretching surface, taking into account the effect of convective surface condition. Using similarity transformations, the governing nonlinear partial differential equations of the physical model are transformed into non-dimensional ordinary differential equations which are solved for local similar solutions using the very robust computer algebra software, Maple 13. The numerical simulation is carried out to investigate the role of the pertinent parameters on the flow and temperature fields as well as on the rate of heat transfer and on the rate of shear stress. The results show that the addition of nanoparticles to the base fluid may not always increase the rate of heat transfer. It depends significantly on the surface convection, type of base fluid and nanoparticles. The finding of this study will open a gate for better understanding of nanofluid characteristics.
\end{abstract}

Keywords: Nanofluid; Convection; Boundary layer; Stretching surface; Similarity solution.

خصائص السوائل التي تحتوي على جزيئات متناهية الصغر وتأثير ها على التدفقات المغتاطيسية والنقل الحراري في الطبقة الحدودية

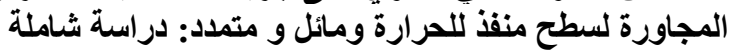

محمد .م. رحمان و محمد .م. الحاتمي

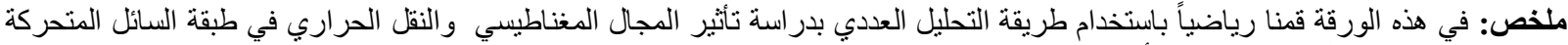

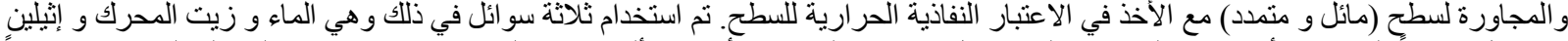

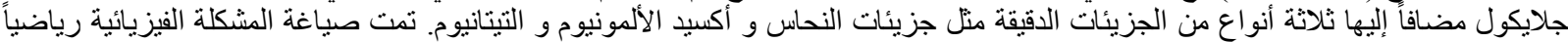

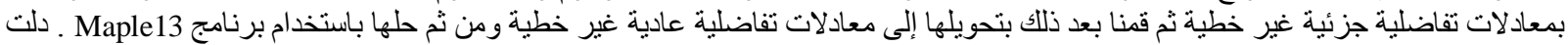

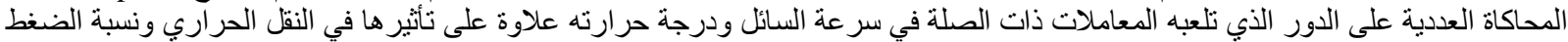

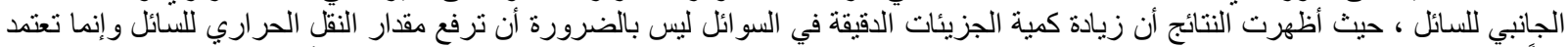

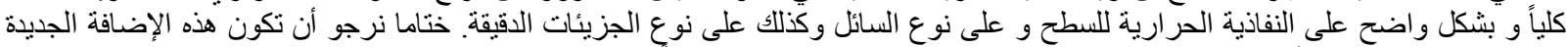

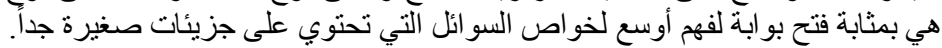
مفتاح الكلمات: سائل يحتوي على جزيئات متتاهية الصغر ، الحمل الحراري،، الطبقة الحدودية، سطح منمدد، الحل المشابه.

1. Introduction

$\mathbf{N}$ anotechnology plays a vital role for the development of $21^{\text {st }}$ century modern micro- and nano-devices. Cooling of these devices is very important for their proper functionality. Increasing the heat transfer efficiency of high-tech devices is desirable as it reduces processing time of work and lengthens the working life of equipment. There are several ways to improve the heat transfer efficiency, such as extended surfaces, application of vibration to the heat transfer surfaces, and usage of micro channels [1]. Heat transfer efficiency can also be improved by increasing the 
thermal conductivity of the working fluid [2]. Commonly used heat transfer fluids such as water, ethylene glycol, and engine oil have relatively low thermal conductivities compared to the thermal conductivity of solids [3]. The high thermal conductivity of solids can be used to increase the thermal conductivity of a fluid by adding small solid particles to that fluid [4]. The feasibility of using of such suspensions of solid particles with sizes of the order of millimeters or micrometers has been investigated by several researchers and significant drawbacks have been observed (see for example, [5]). These drawbacks are sedimentation of particles, clogging of channels, erosion in channel walls, and formation of agglomerate particles, all of which have prevented the practical application of suspensions of solid particles in base fluids as advanced working fluids in heat transfer applications [1,6]. Recent advances in nanotechnology have allowed researchers to study the next generation heat transfer nanofluids, which consist of a base fluid containing a suspension of ultra-fine nanometer-sized (usually less than $100 \mathrm{~nm}$ ) solid particles. Nanoparticles used in nanofluids have been made of various materials, such as oxide ceramics $\left(\mathrm{Al}_{2} \mathrm{O}_{3}, \mathrm{CuO}\right)$, nitride ceramics $(\mathrm{AlN}$, $\mathrm{SiN})$, carbide ceramics $(\mathrm{SiC}, \mathrm{TiC})$, metals $(\mathrm{Cu}, \mathrm{Ag}, \mathrm{Au}, \mathrm{Fe})$, semiconductors $\left(\mathrm{TiO}_{2}, \mathrm{SiC}\right)$, carbon nanotubes, and composite materials such as alloyed nanoparticles $\left(A l_{70} C u_{30}\right)$ or nanoparticle core-polymer shell composites [7]. 'Nanofluids' is the term coined [8] to describe this new class of nanotechnology based heat transfer fluid that exhibits thermal properties superior to those of their host fluids or of conventional particle fluid suspensions. Nanofluids offer several benefits; for example, higher cooling rates, smaller and lighter cooling systems, reduced inventory of heat transfer fluids, decreased pumping-power needs, reduced friction coefficient, and improved wear resistance [7]. The references on nanofluids can be found in the book [7,9], and in the review papers [10-15], among others.

Numerous researchers have studied and reported results on convective heat transfer in nanofluids considering various flow and thermal conditions in different geometries; these include Tiwari and Das [3], Abu-Nada [16], Oztop and Abu-Nada [17], Nield and Kuznetsov [18], Abu-Nada and Oztop [19], Congedo et al. [20], Kuznetsov and Nield [21- 22], Muthtamilselvan et al. [23], Bachok et al. [24], Ahmad and Pop [25], Khan and Pop [26], Beg et al. [27], Gorla et al. [28], Gorla and Chamka [29], Rashidi et al. [30], Rahman et al. [31], Rahman and Aziz [32], Rahman and Eltayeb [33], Rahman et al. [34-36], to mention a few only.

The objective of this paper is to extend the very recently published paper [36] on the boundary layer flow of a nanofluid over an inclined nonlinear stretching sheet in the presence of an applied magnetic field and convective boundary condition. It should be mentioned that the flow and heat transfer characteristics due to the stretching sheet has been of great interest to the researchers. A variety of technical processes are involved in the production of sheeting material, including both metal and polymer sheets. The rate of heat transfer at the sheet is largely dependent on the quality of the final product. The dynamics of the boundary layer flow over a stretching sheet became a popular area of research after the pioneering work of Crane [37], due to its engineering applications in polymer technology and metallurgy, as creating a final product with the desired characteristics depends on the rate of cooling and on the process of stretching. In fact Crane's problem, in which the sheet is stretched with the velocity linearly proportional to the distance from the origin, has been considered for several other features such as viscoelasticity, heat and mass transfer, porosity and magnetic field [38]. Several authors have studied the thermal boundary layer flow and heat transfer of a viscous (regular) fluid, with or without the convective boundary condition, over a nonlinear stretching surface. Yao et al. [39] studied the boundary layer flow near a stagnation-point on a heated permeable stretching surface in a porous medium saturated with a nanofluid in the presence of heat generation and absorption, considering the usual viscous fluid model [40]. In their model the effects of Brownian diffusion and thermophoresis were neglected. Following this Rahman and Aziz [32] studied natural convection heat transfer in a nanofluid over a stretching cylinder. They have shown that the presence of nanoparticles reduces the thickness of the hydrodynamic boundary layer and enhances the heat transfer rate.

On the other hand, a literature survey indicates that the flow analysis of a nanofluid over a nonlinear stretching sheet has been less studied. Thus the aim of this work is to present a theoretical study of a hydromagnetic boundary layer flow and convective heat transfer of a nanofluid over an impermeable nonlinear stretching sheet with convective boundary condition at the surface. In certain polymeric (plastic films, artificial fibers) and metallurgical processes, nonlinear stretching effects are very important, as the final product is strongly influenced by the stretching rate. Thus, the main focus of the analysis is to investigate how the flow and temperature fields of a nanofluid within the boundary layer are influenced by the nonlinearity of the sheet, applied magnetic field, buoyancy force, empirical shape factor of the nanoparticles, and convective boundary condition, varying different base fluids and nanoparticles. In this respect this study is unique and the results are more realistic and practically useful.

The organization of the remainder of the paper is as follows. In Section 2 we describe the physical model and governing equations, and discuss the non-dimensionalization of the governing equations. Section 3 discusses the solution method for finding the local similarity solution of the non-dimensional governing equations which are derived in Section 2. Here we also present the detailed worksheet of Maple 13 used to solve our problem. The numerical results obtained in Section 3 are illustrated graphically and presented in Section 4, where we discuss important hydrodynamic and thermal features of the flow. The results are also discussed from the physical and engineering points of view. Section 5 highlights the important conclusions derived from the present study. 


\section{Physical model}

In the boundary layer analysis of nanofluids two types of models, Buongiorno [10] and Tiwari and Das [3] (herein and after referred as TD), are widely used. In the Buongiorno model the effects of thermophoresis and Brownian motion are taken into account, while in the TD model no such effects are considered, due to the smallness of such parameter values. The TD model is more useful and applicable because of the availability of most of the data relating to the thermal properties of the nanofluid. Thus, the principal aim of this work is to investigate the dynamics of nanofluids over an inclined nonlinear stretching surface in the presence of a convective surface under the action of an applied magnetic field, taking into account viscous dissipation and Joule heating, using the TD model. Three types of nanoparticles, $\mathrm{Cu}, \mathrm{Al}_{2} \mathrm{O}_{3}$ and $\mathrm{TiO}_{2}$, having different shapes (cylindrical, spherical and arbitrary) are dispersed in three base fluids, water $\left(\mathrm{H}_{2} \mathrm{O}\right)$, ethylene glycol $(E G)$, and engine oil $(E O)$, to produce nanofluids. In this section we formulate the physical model with appropriate boundary conditions and non-dimensionalization of the governing equations and, discuss the significance of the important physical and engineering parameters related to the model.

\subsection{Governing equations}

Consider the steady two-dimensional boundary layer flow of a nanofluid in the region $y>0$ moving with uniform velocity $u_{\infty}$ driven by the pressure gradient over a heated stretching sheet. The surface of the sheet is inclined with an acute angle $\alpha$ to the horizontal. The $x$-axis is taken along the sheet along the downstream direction, and the $y$ axis is taken normal to it. Two equal and opposite forces are applied to the sheet to keep the origin fixed. The physical regime is illustrated in Figure 1. The lower surface of the sheet is heated by convection currents from a hot fluid that is different from the studied nanofluid at temperature $T_{0}$ which provides the heat transfer coefficient $h$. A magnetic field of uniform strength $B_{0}$ is applied in the $y$-direction, i.e., normal to the flow direction. The magnetic Reynolds number is assumed to be small, so the induced magnetic field can be neglected.

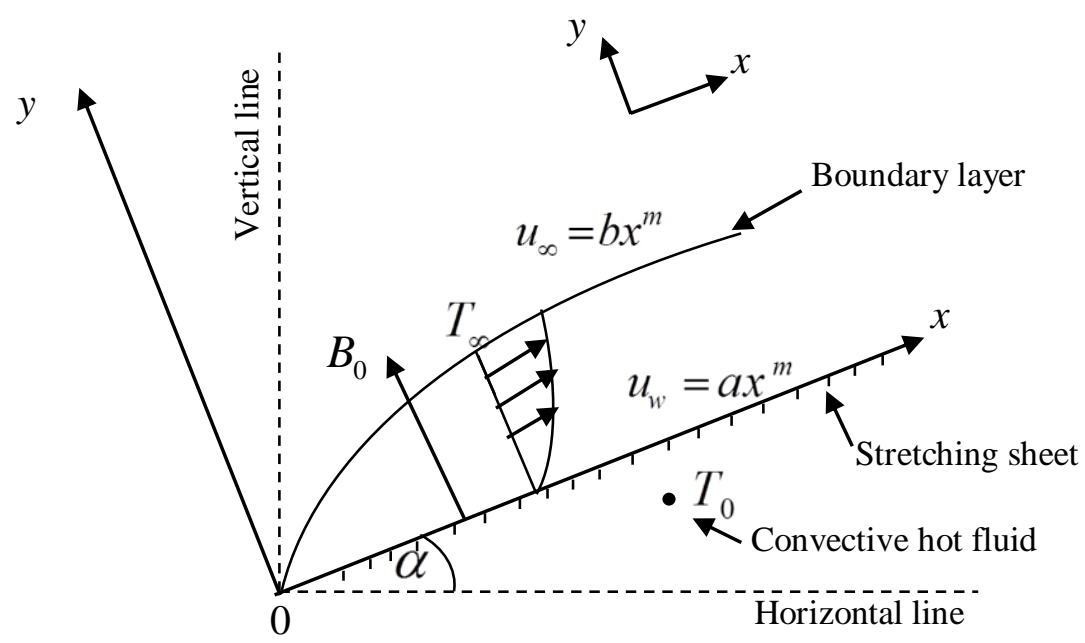

Figure 1. Flow configurations and coordinate system.

The external velocity $u_{\infty}$ and pressure gradient $\frac{\partial p}{\partial x}$ of the free stream are given by:

$$
\begin{aligned}
& u_{\infty}=b x^{m} \\
& \frac{\partial p}{\partial x}=-\rho_{n f} u_{e} \frac{d u_{e}}{d x}
\end{aligned}
$$

The surface velocity $u_{w}$ of the sheet is considered to be:

$$
u=u_{w}(x)=a x^{m}
$$


where $a$ is a dimensional positive constant known as the stretching coefficient, $b$ is defined as a function of the flow geometry and $m$ is an arbitrary positive constant.

Under the boundary layer approximations, the governing equations of the problem become (Rahman et al. [31, 36]):

$$
\begin{gathered}
\frac{\partial u}{\partial x}+\frac{\partial v}{\partial y}=0 \\
u \frac{\partial u}{\partial x}+v \frac{\partial u}{\partial y}=-\frac{1}{\rho_{n f}} \frac{\partial p}{\partial x}+v_{n f} \frac{\partial^{2} u}{\partial y^{2}}+g \sin \alpha \frac{\left(T-T_{\infty}\right)}{\rho_{n f}} \\
{\left[\varphi\left(\rho \beta^{*}\right)_{s p}+(1-\varphi)\left(\rho \beta^{*}\right)_{b f}\right]-\frac{\sigma B_{0}^{2} u}{\rho_{n f}}} \\
u \frac{\partial T}{\partial x}+v \frac{\partial T}{\partial y}=\alpha_{n f} \frac{\partial^{2} T}{\partial y^{2}}+\frac{v_{n f}}{\left(c_{p}\right)_{n f}}\left(\frac{\partial u}{\partial y}\right)^{2}+\frac{\sigma B_{0}^{2} u^{2}}{\left(\rho c_{p}\right)_{n f}}
\end{gathered}
$$

where $u, v$ are the velocity components along $x, y$ coordinates, respectively. Here $v_{n f}=\frac{\mu_{n f}}{\rho_{n f}}$ is the kinematic coefficient of viscosity of the nanofluid, $\mu_{n f}$ is the viscosity of the nanofluid, $\rho_{n f}$ is the density of the nanofluid, $\alpha_{n f}$ is the thermal diffusivity of the nanofluid, $\kappa_{n f}$ is the thermal conductivity of the nanofluid, $\left(\rho c_{p}\right)_{n f}$ is the heat capacity of the nanofluid, $T$ is temperature of the nanofluid within the boundary layer, $\sigma$ is the magnetic permeability, and $\beta^{*}$ is the volume expansion coefficient of the nanofluid.

The term $\left[g \sin \alpha\left(T-T_{\infty}\right)\left(\varphi\left(\rho \beta^{*}\right)_{s p}+(1-\varphi)\left(\beta^{*} \rho\right)_{b f}\right)\right]$ in equation (5) accounts for thermal buoyancy due to the thermal expansion of the base fluid and due to the difference in density of the nanoparticles. The last term in the right-hand side of equation (5) $\left[-\sigma B_{0}{ }^{2} u\right]$ is due to the applied magnetic field. The interaction of the fluid velocity $(\boldsymbol{u})$ and applied magnetic field $(\mathbf{B})$ creates a Lorentz force, $\mathbf{J} \times \mathbf{B}$, where the electric current density follows the generalized Ohm's law, $\mathbf{J}=\sigma(\mathbf{E}+\boldsymbol{u} \times \mathbf{B}), \sigma$ is the electrical conductivity, and $\mathbf{E}$ is the electric field. For an applied magnetic field $\mathbf{B}=\left(0, B_{0}, 0\right)$, fluid velocity $\boldsymbol{u}=(u, v, 0)$, and in the absence of any electric field ( $\mathbf{E}=\mathbf{0}$ ) (since the surface is electrically non-conducting), the $x$-component of the Lorentz force yields $\left(-\sigma B_{0}{ }^{2} u\right)$.

Equation (6) states that heat can be transported in a nanofluid by convection - the left-hand side $\left(u \frac{\partial T}{\partial x}+v \frac{\partial T}{\partial y}\right)$, by conduction first term on the right-hand side $\left(\alpha_{n f} \frac{\partial^{2} T}{\partial y^{2}}\right)$ and by virtue of viscous dissipation $\frac{v_{n f}}{\left(c_{p}\right)_{n f}}\left(\frac{\partial u}{\partial y}\right)^{2}$, and also by Joule heating $\frac{\sigma B_{0}^{2} u^{2}}{\left(\rho c_{p}\right)_{n f}}$.

The effective dynamic viscosity $\mu_{n f}$, density $\rho_{n f}$, volumetric coefficient of thermal expansion $\beta_{n f}^{*}$, thermal diffusivity $\alpha_{n f}$, and the heat capacitance $\left(\rho c_{p}\right)_{n f}$ of the nanofluid are given by:

$$
\begin{gathered}
\mu_{n f}=\frac{\mu_{b f}}{(1-\varphi)^{2.5}}(\text { Brinkman [41]) } \\
\rho_{n f}=(1-\varphi) \rho_{b f}+\varphi \rho_{s p} \quad \text { (Xuan and Li [42]) } \\
\left(\rho c_{p}\right)_{n f}=(1-\varphi)\left(\rho c_{p}\right)_{b f}+\varphi\left(\rho c_{p}\right)_{s p} \text { (Xuan and Li [42]) }
\end{gathered}
$$




$$
\begin{aligned}
& \left(\rho \beta^{*}\right)_{n f}=(1-\varphi) \rho_{b f} \beta_{b f}^{*}+\varphi \rho_{s p} \beta_{s p}^{*} \text { (Mansour and Ahmed [43]) } \\
& \alpha_{n f}=\frac{\kappa_{n f}}{\left(\rho c_{p}\right)_{n f}} \\
& \frac{\kappa_{n f}}{\kappa_{b f}}=\frac{\kappa_{s p}+(n-1) \kappa_{b f}-(n-1)\left(\kappa_{b f}-\kappa_{s p}\right) \varphi}{\kappa_{s p}+(n-1) \kappa_{b f}+\left(\kappa_{b f}-\kappa_{s p}\right) \varphi} \text { (Rana and Bhargava [44]) }
\end{aligned}
$$

The subscripts $b f$ and $n f$, respectively, stand for base fluid and nanofluid, whereas $s p$ stands for solid particles, and $n$ is the empirical shape parameter.

\subsection{Boundary conditions}

The boundary conditions for the above-stated model are

(i) on the surface of the sheet $(y=0)$

$$
u=u_{w}=a x^{m}, v=0,-\kappa_{n f} \frac{\partial T}{\partial y}=h\left(T-T_{0}\right)
$$

(ii) matching with the free stream $(y \rightarrow \infty)$

$$
u \rightarrow u_{\infty}=b x^{m}, \quad T \rightarrow T_{\infty}
$$

where the subscript $w$ refers to the sheet surface, and $\infty$ refers to the boundary layer edge.

\subsection{Introduction of dimensionless variables}

In order to make equations (4)-(6) and (13)-(14) dimensionless, we introduce the following dimensionless variables:

$$
\eta=y \sqrt{\left(\frac{m+1}{2}\right) \frac{u_{w}}{v_{b f} x}}, \psi(x, y)=\sqrt{\frac{2 v_{b f} x u_{w}}{m+1}} f(\eta) \text { and } \theta(\eta)=\frac{T-T_{\infty}}{T_{0}-T_{\infty}}
$$

where $\psi$ is the stream function and $v_{b f}=\frac{\mu_{b f}}{\rho_{b f}}$ is the kinematic viscosity of the base fluid. The function $f$ is the nondimensional stream function. The stream function $\psi$ satisfies the relations

so as to satisfy the continuity equation (4).

$$
u=\frac{\partial \psi}{\partial y} \text { and } v=-\frac{\partial \psi}{\partial x}
$$

From equations (15) and (16), we obtained the following expressions

$$
\begin{gathered}
u=u_{w} f^{\prime}(\eta) \\
v=-\sqrt{\frac{(m+1)}{2} \frac{v_{b f} u_{w}}{x}}\left[f+\left(\frac{m-1}{m+1}\right) \eta f^{\prime}\right] .
\end{gathered}
$$

\subsection{Non-dimensional governing equations}

Now substituting equations (7)-(12) and (15)-(18) into equations (5)-(6), we obtain

$$
\begin{gathered}
f^{\prime \prime \prime}+A f f^{\prime \prime}+A\left(\frac{2 m}{m+1}\right)\left(\varepsilon^{2}-f^{\prime 2}\right)+\left(\frac{2}{m+1}\right) \gamma A B(\sin \alpha) \theta-\left(\frac{2}{m+1}\right) C H a f^{\prime}=0 \\
\theta^{\prime \prime}+\operatorname{Pr} D E f \theta^{\prime}+\operatorname{Pr} E E c C^{-1} f^{\prime \prime 2}+\left(\frac{2}{m+1}\right) \operatorname{Pr} E c H a E f^{\prime 2}=0
\end{gathered}
$$

where the constants $A, B, C, D$, and $E$ are defined by

$$
A=(1-\varphi)^{2.5}\left[1-\varphi+\varphi\left(\frac{\rho_{s p}}{\rho_{b f}}\right)\right]
$$




$$
\begin{gathered}
B=\frac{1-\varphi+\varphi\left(\frac{\rho_{s p}}{\rho_{b f}}\right)\left(\frac{\beta_{s p}^{*}}{\beta_{b f}^{*}}\right)}{1-\varphi+\varphi\left(\frac{\rho_{s p}}{\rho_{b f}}\right)} \\
C=(1-\varphi)^{2.5} \\
D=1-\varphi+\varphi \frac{\left(\rho c_{p}\right)_{s p}}{\left(\rho c_{p}\right)_{b f}} \\
E=\frac{\kappa_{b f}}{\kappa_{n f}}=\frac{\kappa_{s p}+(n-1) \kappa_{b f}+\left(\kappa_{b f}-\kappa_{s p}\right) \varphi}{\kappa_{s p}+(n-1) \kappa_{b f}-(n-1)\left(\kappa_{b f}-\kappa_{s p}\right) \varphi}
\end{gathered}
$$

The dimensionless parameters which appear in equations (19)-(20) are as follow: $\gamma=\frac{G r_{b f}}{\left(\operatorname{Re}_{b f}\right)^{2}}$ is the thermal buoyancy parameter, $G r_{b f}=\frac{g \beta_{b f}^{*}\left(T_{0}-T_{\infty}\right) x^{3}}{v_{b f}^{2}}$ is the local thermal Grashof number corresponding to the base fluid, $\operatorname{Re}_{b f}=\frac{u_{w} x}{v_{b f}}$ is the local Reynolds number corresponding to the base fluid, $H a=\frac{\sigma B_{0}^{2} x}{\rho_{b f} u_{w}}$ is the modified Hartmann number or local magnetic field parameter, $\varepsilon=\frac{b}{a}$ is the ratio of the external free stream velocity to the velocity of the stretching surface, $\operatorname{Pr}=\frac{v_{b f}}{\alpha_{b f}}$ is the Prandtl number, and $E c=\frac{u_{w}^{2}}{\left(c_{p}\right)_{b f}\left(T_{0}-T_{\infty}\right)}$ is the Eckert number.

\subsection{Non-dimensional boundary conditions}

The boundary conditions (13)-(14) in their nondimensional form become

$$
\begin{gathered}
f(0)=0, f^{\prime}(0)=1, \theta(0)=1+\sqrt{\frac{m+1}{2}}\left(\frac{1}{E B i}\right) \theta^{\prime}(0) \\
f^{\prime}(\infty)=\varepsilon, \theta(\infty)=0
\end{gathered}
$$

The dimensionless parameter $B i$ is defined by

$$
B i=\frac{h x}{\kappa_{b f}} \operatorname{Re}_{b f}^{-\frac{1}{2}}
$$

The Biot number $(B i)$ signifies the ratio of the convection at the surface to conduction within the body, otherwise it is the ratio of the internal resistance of a body to heat conduction to its external resistance to heat convection. Therefore, a small Biot number represents low resistance to heat conduction, and thus small temperature gradients within the body.

\subsection{Rate of shear stress and rate of heat transfer}

\subsubsection{Skin-friction coefficient}

The boundary layer normally generates a drag on the surface as a result of the viscous stresses which are developed at the wall. This drag is normally referred to as skin friction. Skin friction occurs from the interaction between the fluid and the skin of the body, and is directly associated with the wetted surface, and the area of the face of the body that is in contact with the fluid. Therefore, skin friction is the force resisting the relative motion of fluid layers and material elements sliding against each other.

The skin- friction coefficient (rate of shear stress) is defined by

$$
C_{f}=\frac{2 \tau}{\rho_{b f} u_{w}^{2}}
$$

where the shear stress at the surface $\tau$ is defined as: 


$$
\tau=\mu_{n f}\left(\frac{\partial u}{\partial y}\right)_{y=0}
$$

By using (15) and (17), equation (29) becomes

\subsubsection{Nusselt number}

$$
C_{f} R_{b f}^{\frac{1}{2}}=\sqrt{\frac{m+1}{2}} \frac{2 f^{\prime \prime}(0)}{(1-\varphi)^{2.5}}
$$

The Nusselt number is the ratio of convective to conductive heat transfer across (normal to) the boundary of the surface. The Nusselt number (or rate of heat transfer) is defined as

$$
N u=\frac{x q_{w}}{\kappa_{b f}\left(T_{0}-T_{\infty}\right)}
$$

where the surface heat flux $q_{w}$ is given by

$$
q_{w}=-\kappa_{n f}\left(\frac{\partial T}{\partial y}\right)_{y=0}
$$

By using (12) and (15), equation (32) can be written as:

$$
N u \operatorname{Re}_{b f}^{\frac{-1}{2}}=-((m+1) / 2)^{\frac{1}{2}}(1 / E) \theta^{\prime}(0)
$$

\section{Numerical Technique}

A similarity solution is one in which the number of variable can be reduced by one or more by some analytical means, usually by a coordinate transformation. The benefit of a similarity analysis is to reduce the set of governing partial differential equations (PDEs) of a physical model into a set of ordinary differential equations (ODEs). In Section 2, the governing equations (4)-(6) of the physical model have two-independent variables, namely $x$ and $y$. To find a similarity solution, we introduced a new variable $\eta$ (Eq. (15) which replaced both $x$ and $y$ in the system. With this substitution, the number of independent variables reduced from two to one and the PDE system (4)-(6) became a system of ordinary differential equations (19) and (20).

\subsection{The numerical code and Maple worksheet}

In this section we discuss in detail the technique to solve the system (19)-(20) together with the boundary conditions (26)-(27). The set of equations (19)-(20) is highly nonlinear and coupled and cannot be solved analytically. Thus, the numerical solutions of them subject to the boundary conditions, (26)-(27) are obtained using the very robust computer algebra software, Maple 13. This software uses a fourth-fifth order Runge-Kutta-Fehlberg method as the default to solve the boundary value problems numerically following the code dsolve. In Maple 13, dsolve is a built-in command which solves the boundary value problems with a certain level of accuracy ( $10^{-6}$ as default). The 'infinity' $\eta \rightarrow \infty$ in the boundary conditions (27) is replaced by a finite value $\eta=\eta_{\infty}$. We started the computation at small value of $\eta$, then subsequently increased the value of $\eta$ until the boundary conditions were verified. For a detailed Maple worksheet see Al-Hatmi [45].

\subsection{Validity of the numerical results}

To check the validity of our numerical results we calculated the values of $\left(2 \operatorname{Re}_{b f} /(m+1)\right)^{1 / 2} C_{f}$ and $\left[(m+1) R e_{b f} / 2\right]^{\frac{-1}{2}} N u$ for various values of $m$ and $\varphi$ keeping all other parameter values fixed. If we consider $\gamma \rightarrow 0, H a \rightarrow 0, E c \rightarrow 0$, then the non-dimensional governing equations (19) and (20) become

$$
\begin{gathered}
f^{\prime \prime \prime}+A f f^{\prime \prime}+A\left(\frac{2 m}{m+1}\right)\left(1-f^{\prime 2}\right)=0, \\
\theta^{\prime \prime}+\operatorname{Pr} D \text { E f } \theta^{\prime}=0 .
\end{gathered}
$$


Table 1. Comparison of the values of $\left(2 R e_{b f} /(m+1)\right)^{\frac{1}{2}} C_{f}$ and $\left[(m+1) R e_{b f} / 2\right]^{\frac{-1}{2}} N u$ with Yacob et al. [46] for different values of $m$ and $\varphi$.

\begin{tabular}{cccccc}
\hline \multirow{2}{*}{$m$} & $\varphi$ & \multicolumn{2}{c}{$\left(2 R e_{b f} /(m+1)\right)^{\frac{1}{2}} C_{f}$} & \multicolumn{2}{c}{$\left[(m+1) R e_{b f} / 2\right]^{\frac{-1}{2}} N u$} \\
\cline { 2 - 6 } & & Present & Yacob et al. [46] & Present & Yacob et al. [46] \\
\hline \multirow{2}{*}{0} & 0.1 & 0.7181 & 0.7179 & 1.1102 & 1.1100 \\
& 0.2 & 0.9993 & 0.9992 & 1.3343 & 1.3342 \\
\cline { 2 - 6 } 0.5 & 0.1 & 1.5882 & 1.5881 & 1.3473 & 1.3472 \\
& 0.2 & 2.2106 & 2.2105 & 1.6048 & 1.6048 \\
\cline { 2 - 6 } 1 & 0.1 & 1.8843 & 1.8843 & 1.4043 & 1.4043 \\
& 0.2 & 2.6227 & 2.6226 & 1.6693 & 1.6692 \\
\hline
\end{tabular}

These equations exactly match with those of Yacob et al. [46]. Now replacing the boundary conditions (26)-(27) with the following

$$
\left.\begin{array}{l}
f(0)=0, f^{\prime}(0)=0, \theta(0)=1 \\
f^{\prime}(\eta) \rightarrow 1, \theta(\eta) \rightarrow 0 \text { as } \eta \rightarrow \infty
\end{array}\right\}
$$

we calculated the reduced shear stress $\left(2 R e_{b f} /(m+1)\right)^{\frac{1}{2}} C_{f}$ and reduced Nusselt number $\left[(m+1) \operatorname{Re}_{b f} / 2\right]^{\frac{-1}{2}} \mathrm{Nu}$ to match with Yacob et al. [46] keeping $\mathrm{Pr}=6.2$ fixed and default nanofluid as $\mathrm{Cu}-\mathrm{H}_{2} \mathrm{O}$. From Table 1 we see that the data produced by our Maple code and those of Yacob et al. [46] are in excellent agreement, and give confidence to use the present code.

\section{Results and discussion}

In section 3, we discussed the code for solving the coupled dimensionless momentum and energy equations (19)(20), subject to the dimensionless boundary conditions (26)-(27). In this section, we discuss the effects of the various non-dimensional parameters, namely angle of inclination $\alpha$, magnetic field parameter $H a$, nanoparticle volume fraction parameter $\varphi$, thermal buoyancy parameter $\gamma$, empirical shape factor $n$, stretching index $m$ and Biot number $B i$ on the velocity and temperature distributions. We also discuss the effects of the same parameters on the Nusselt number and skin-friction coefficient. We carry out the numerical simulations for three different types of base fluids namely: water $\left(\mathrm{H}_{2} \mathrm{O}\right)$, engine oil $(\mathrm{EO})$ and ethylene glycol $(E G)$ with three different kinds of nanoparticles, namely $\mathrm{Cu}$, $\mathrm{Al}_{2} \mathrm{O}_{3}$ and $\mathrm{TiO}_{2}$. The thermophysical properties of the base fluids and solid nanoparticles (Oztop and Abu-Nada [17], Rahman et al. [31], Al-Hatmi [45]) are given in Table 2.

Table 2. Thermophysical properties of the base fluids and solid nanoparticles.

\begin{tabular}{ccccccc}
\hline Physical properties & $\begin{array}{c}\text { Water } \\
\mathrm{H}_{2} \mathrm{O}\end{array}$ & $\begin{array}{c}\text { Ethylene Glycol } \\
\text { EG }\end{array}$ & $\begin{array}{c}\text { Engine oil } \\
\text { EO }\end{array}$ & $\mathrm{Cu}$ & $\mathrm{Al}_{2} \mathrm{O}_{3}$ & $\mathrm{TiO}_{2}$ \\
\hline$C_{p}[\mathrm{~J} / \mathrm{kgK}]$ & 4179 & 2382.1 & 1880.3 & 385 & 765 & 686.2 \\
$\rho\left[\mathrm{kg} / \mathrm{m}^{3}\right]$ & 997.1 & 1117.48 & 888.23 & 8933 & 3970 & 4250 \\
$\kappa[\mathrm{W} / \mathrm{mK}]$ & 0.613 & 0.2492 & 0.145 & 400 & 40 & 8.9538 \\
$\mu\left[\mathrm{Ns} / \mathrm{m}^{2}\right]$ & 0.001003 & 0.022 & 0.8451 & - & - & - \\
$\beta^{*} \times 10^{-5}[1 / \mathrm{K}]$ & 21 & 57 & 70 & 1.67 & 0.85 & 0.9 \\
$\alpha_{b f, n f} \times 10^{7}\left[\mathrm{~m}^{2} / \mathrm{s}\right]$ & 1.47 & 0.94868 & 0.868 & 1163.1 & 131.7 & 30.7 \\
$P r$ & 6.8377 & 210.2978 & 10958.9 & - & - & - \\
\hline
\end{tabular}




\subsection{Computational results for fluid velocity and temperature distributions}

\subsubsection{Velocity profiles in $\mathrm{Cu}-\mathrm{H}_{2} \mathrm{O}$ nanofluid}

The numerical values of the nondimensional $x$-component of the translational velocity as a function of $\eta$ are illustrated in Figures 2 to 6 for different values of the angle of inclination $\alpha$, magnetic field parameter $H a$, nanoparticle volume fraction parameter $\varphi$, thermal buoyancy parameter $\gamma$, empirical shape factor $n$, stretching index $m$ and Biot number $B i$ respectively. Since there is almost no experimental data, the choice of the values of the parameters was dictated by the values chosen by previous investigators. The default values of the parameters are considered as $\alpha=\pi / 4, H a=0.5, \varphi=2 \%, \gamma=5, n=3, m=2$, and $B i=0.5$. In the simulation we also consider $\mathrm{Cu}-\mathrm{H}_{2} \mathrm{O}$ as default nanofluid unless otherwise specified. The value of the Prandtl number $\operatorname{Pr}$ is kept 6.8 (at the room temperature).

In Figure 2 we present the nondimensional $x$-component of the translational velocity profiles against $\eta$ for different values of the angle of inclination $\alpha$ keeping all other parameter values (stated above) fixed. The value $\alpha=0$ corresponds to a flat horizontal surface, whereas $\alpha=\pi / 2$ corresponds to a vertical surface. It is found that the nondimensional velocity of the nanofluid increases with the increase of the angle of inclination $\alpha$ while the thickness of the hydrodynamic boundary layer is found to decrease with the increase of $\alpha$. This is due to the fact that, as $\alpha$ increases, the thermal buoyancy of the fluid increases, which in turn induces the fluid velocity. From equation (19) we see that the buoyancy force is multiplied by $\sin \alpha$, which attains its maximum value when $\alpha=\pi / 2$. Thus, the velocity profiles squeeze closer and closer to the boundary layer.

Figure 3 presents the impact of the applied magnetic field on the nanofluid flow keeping all other parameter values fixed. The magnetic field parameter (or modified Hartmann number) $\mathrm{Ha}$ is a ratio of the electromagnetic force to the viscous force, which measures the strength of the applied magnetic field.

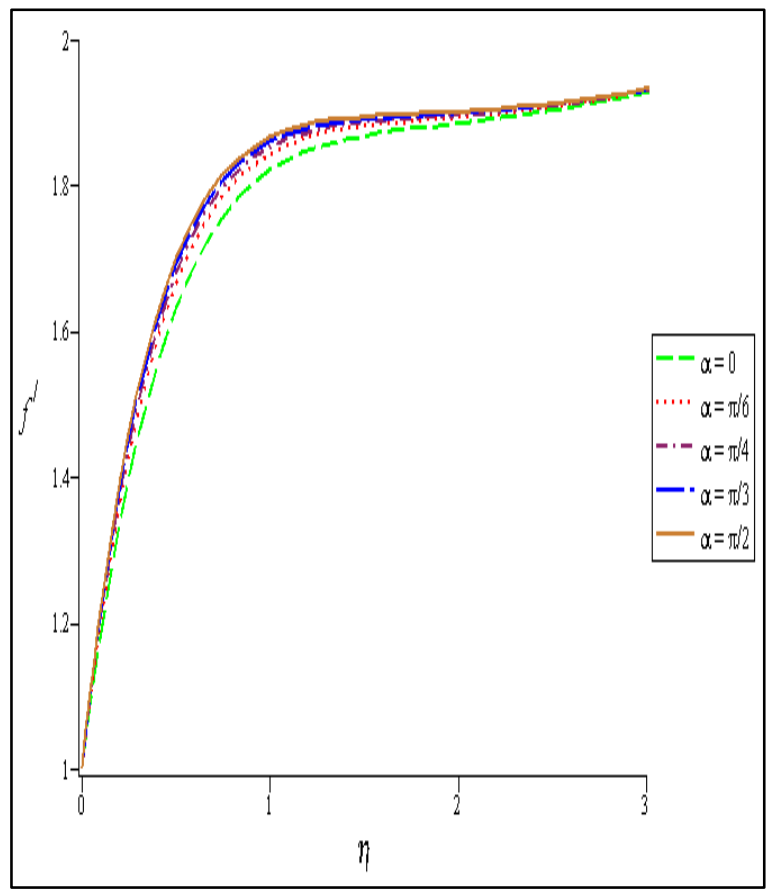

Figure 2. Velocity profiles for different values of $\alpha$.

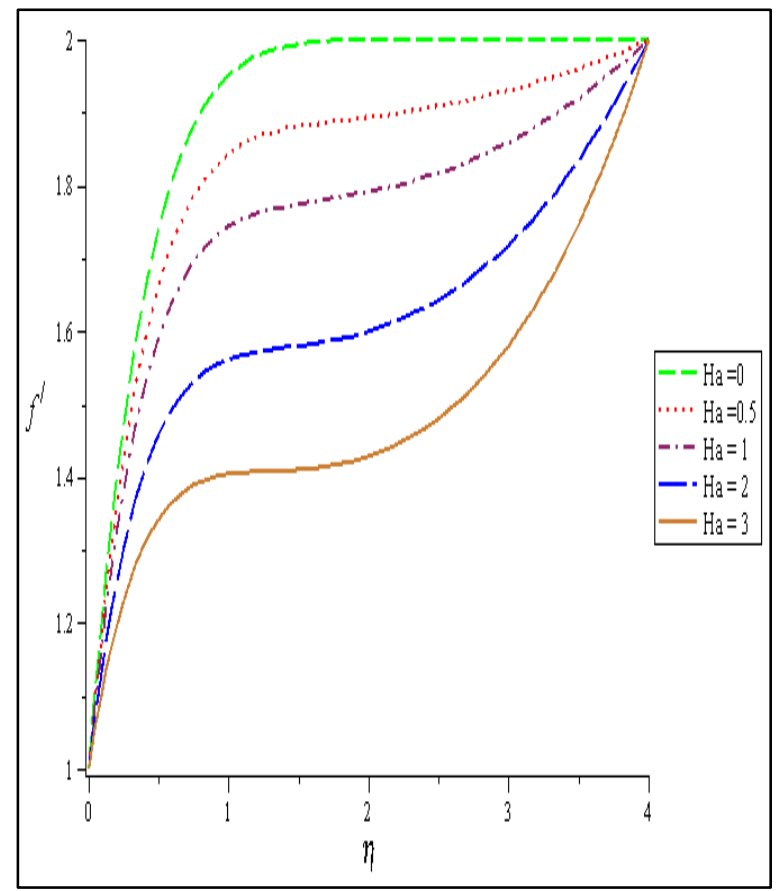

Figure 3. Velocity profiles for different values of $\mathrm{Ha}$. 


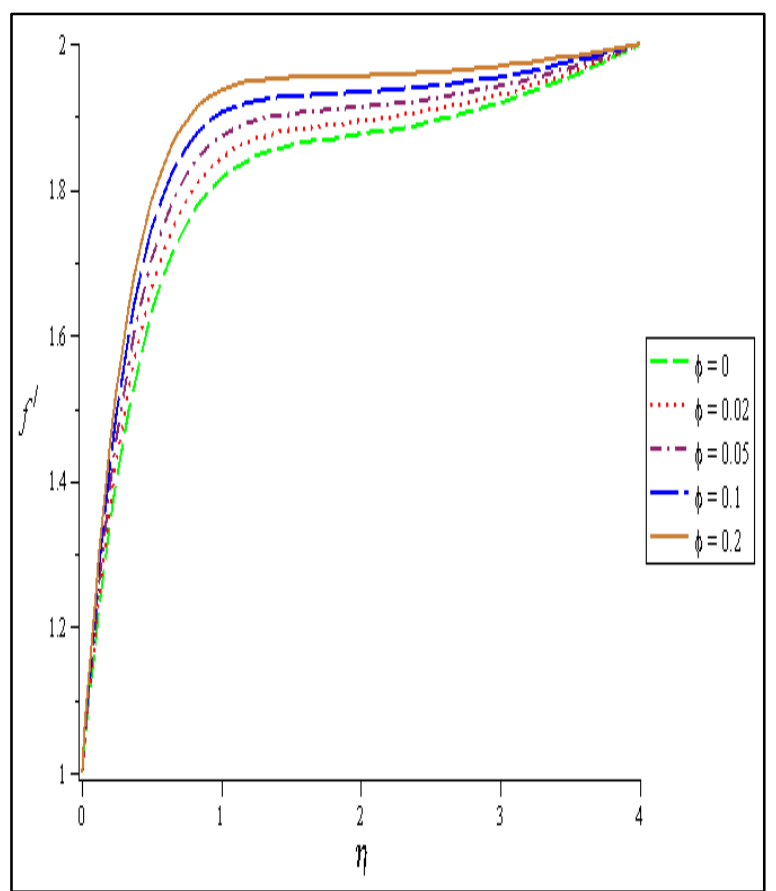

Figure 4. Velocity profiles for different values of $\varphi$.

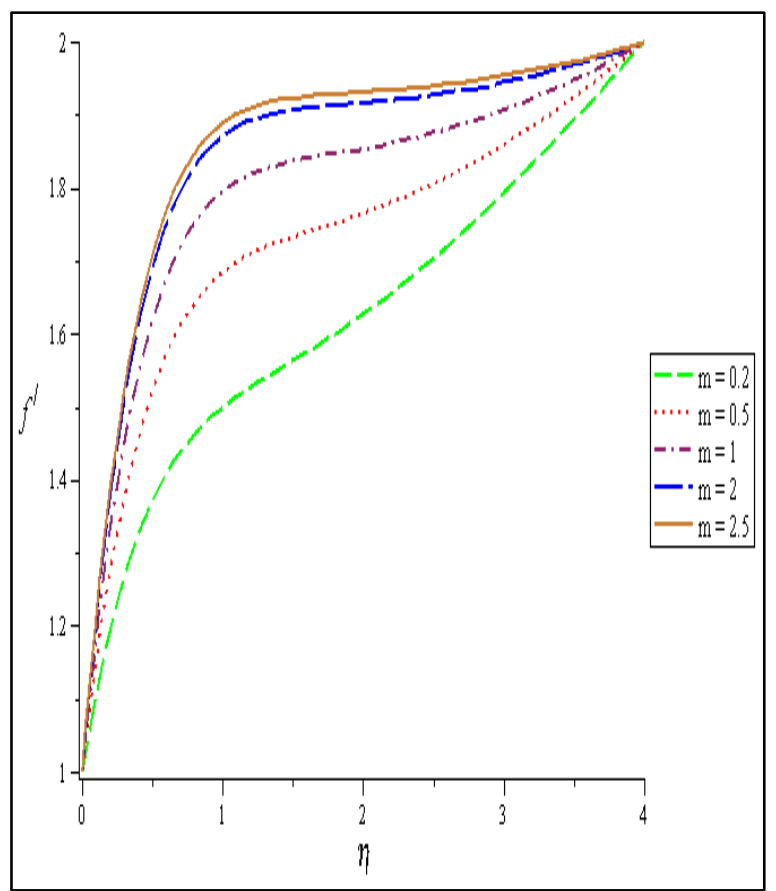

Figure 6. Velocity profiles for different values of $m$.

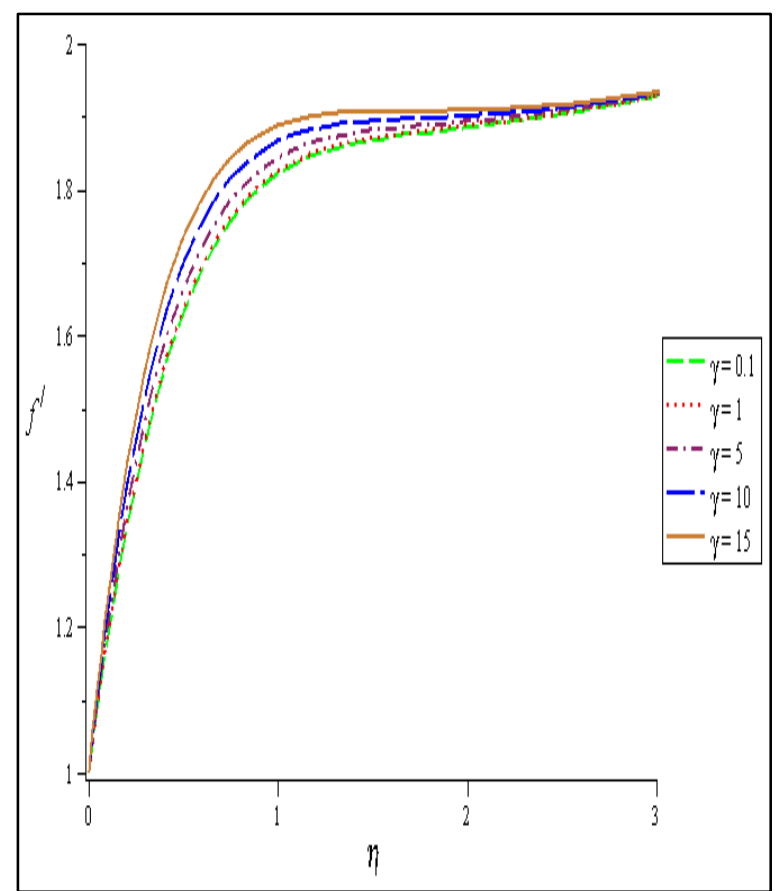

Figure 5. Velocity profiles for different values of $\gamma$.

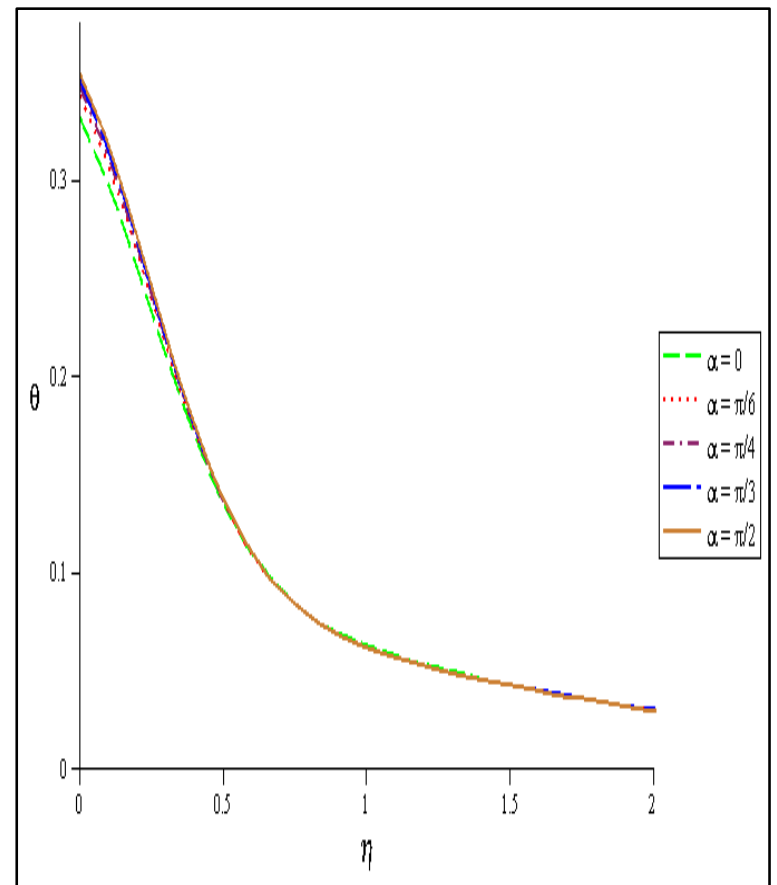

Figure 7. Temperature profiles for different values of $\alpha$.

An increase in $\mathrm{Ha}$ intensifies the strength of the applied magnetic field. Figure 3 reveals that maximum fluid flow occurs in the absence of the magnetic field $(\mathrm{Ha}=0)$. In the presence of a magnetic field, fluid velocity reduces. This is due to the fact that an applied magnetic field on the flow domain creates a Lorentz force which acts like strings to retard the fluid motion. Thus, fluid velocity may be controlled by just controlling the strength of the applied magnetic field. 
In Figure 4 we present the variations of the nanoparticle volume fraction on the flow field. The value $\varphi=0$ corresponds to a clear fluid, i.e. without nanoparticles. It is found that the velocity of the nanofluid increases with the increase of the nanoparticle volume fraction. Figure 4 also shows the significant effect of $\varphi$ on the hydrodynamic boundary layer thickness, i.e., the thickness of the hydrodynamic boundary layer of the nanofluid decreases with the increase of the nanoparticle volume fraction.

The effect of the thermal buoyancy parameter $\gamma$ on the nondimensional $x$-component of the translational velocity of the nanofluid within the boundary layer is presented graphically in Figure 5. In this figure we observe the remarkable increasing effect of $\gamma$ on the nanofluid velocity. As the buoyancy force intensifies, the thickness of the hydrodynamic boundary layer decreases.

The effect of the stretching parameter $m$ on the nanofluid velocity is displayed in Figure 6. In this figure we observe again the remarkable effect of $m$ on the nanofluid velocity, i.e. the nondimensional velocity increases very rapidly with the increase of $m$. The thickness of the hydrodynamic boundary layer decreases with the increase of $m$. Thus, by changing the nonlinearity of the stretching surface we may control the growth of the boundary layer.

\subsubsection{Temperature profiles in $\mathrm{Cu}-\mathrm{H}_{2} \mathrm{O}$ nanofluid}

The effects of the pertinent parameters on the temperature profiles of the water-based nanofluid containing $\mathrm{Cu}$ nanoparticles are presented in Figures 7 to 13. Figure 7 displays the nondimensional temperature profiles within the boundary layer for different values of the angle of inclination: $\alpha=0$ (flat plate), $\alpha=\pi / 6\left(30^{\circ}\right), \alpha=\pi / 4\left(45^{\circ}\right)$, $\alpha=\pi / 3\left(60^{\circ}\right), \alpha=\pi / 2\left(90^{\circ}\right)$ (stagnation flow). From this figure, it can be seen that the temperature of the nanofluid increases with the increase of $\alpha$. It is also found that the maximum temperature of the nanofluid is obtained for a stagnation point flow and the minimum value is obtained for the flow over a flat plate. The temperature of the nanofluid within the boundary layer decreases monotonically with the increase of $\eta$.

Figure 8 shows temperature profiles for different values of the magnetic field parameter, i.e. modified Hartmann number $H a$. It is found that the temperature of the nanofluid increases monotonically as $H a$ increases. The thickness of the thermal boundary layer also increases with the increase of the strength of the applied magnetic field $H a$. Thus the surface temperature of the sheet can be controlled by controlling the strength of the applied magnetic field. An applied magnetic field retards the fluid motion, which results in an increase of the fluid temperature.

In Figure 9 we present the effect of the nanoparticles volume fraction $\varphi$ on the temperature profiles within the boundary layer. Here we varied the nanoparticle volume fraction from $0 \%$ to $20 \%$ of the total volume of the fluid. It is found that the temperature of the nanofluid increases with the increase of nanoparticles volume fraction $\varphi$. It can further be noted that the temperature of the base fluid $(\varphi=0)$ is lower than the temperature of the nanofluid since the thermal conductivity of the base fluid increases with the addition of solid nanoparticles in it. As their volume fraction increases, the nanoparticles absorb more heat from the surface of the sheet, and as a consequence, the fluid temperature increases in the vicinity of the wall.

The thermal buoyancy parameter $\gamma$ is a ratio of the buoyancy force to the viscous force. The value $\gamma<<1$ corresponds to forced convection in which viscous forces are dominant compared to the buoyancy forces, whereas $\gamma=1$ corresponds to mixed convection in which viscous forces and buoyancy forces are of comparable size. On the other hand $\gamma \gg 1$ corresponds to free convection, or the so-called natural convection, in which buoyancy forces are dominant. The effect of the thermal buoyancy parameter on the nondimensional temperature profiles within the boundary layer is presented in Figure 10. Figure 10 shows that temperature within the boundary layer increases monotonically irrespective of the types of convection. We further notice that the thickness of the thermal boundary layer increases with the increase of the value of $\gamma$. This is due to the fact that as $\gamma$ increases, the thermal state of the fluid also increases, which in turn increases the heat transfer rate from the surface of the sheet to the fluid.

Figure 11 represents the temperature profiles for various values of the empirical shape factor $n$ of the nanoparticles. It can be seen that the nanofluid temperature decreases as the empirical shape factor increases when $0 \leq \eta \leq 0.3$. As the shape factor increases, the nanoparticles absorb more heat from the surface of the sheet, and as a consequence, the fluid temperature decreases in the vicinity of the sheet. On the other hand, away $(\eta \geq 0.3)$ from the surface of the sheet, the temperature of the nanofluid increases with the increase of empirical shape factor. The value $n=3 / 2$ represents cylindrical shaped nanoparticles, whereas $n=3$ represents spherical shaped ones. The other values correspond to arbitrary shaped nanoparticles. We notice that, in the vicinity of the surface, nanofluid temperature is higher for cylindrical shaped nanoparticles than for spherical shaped nanoparticles. It is worth mentioning that nanofluid velocity was not affected by the shape of the nanoparticles, hence is not depicted.

Figure 12 depicts the variation of the temperature profiles within the boundary layer for various values of the stretching index $m$. The value $m=0$ corresponds to a uniformly moving surface. Here, we consider only the positive values of $m$ (stretching surface). Figure 12 reveals that the temperature profiles within the boundary layer decrease quite rapidly with the increase of the stretching index $m$. From Figure 6 we noted that nanofluid velocity increases with the increase of the stretching index $m$. Thus, fast fluid motion carries less heat from the surface of the sheet to the 
boundary layer, and as a consequence, fluid temperature within the boundary layer decreases. The thickness of the thermal boundary layer decreases with the increase of the stretching index.

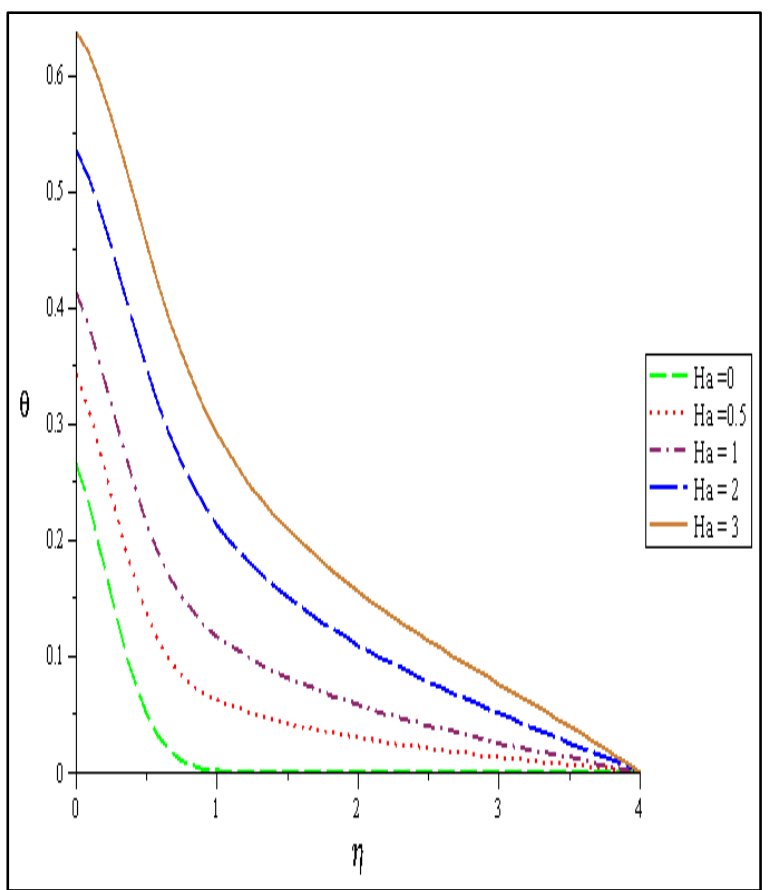

Figure 8. Temperature profiles for different values of $\mathrm{Ha}$.

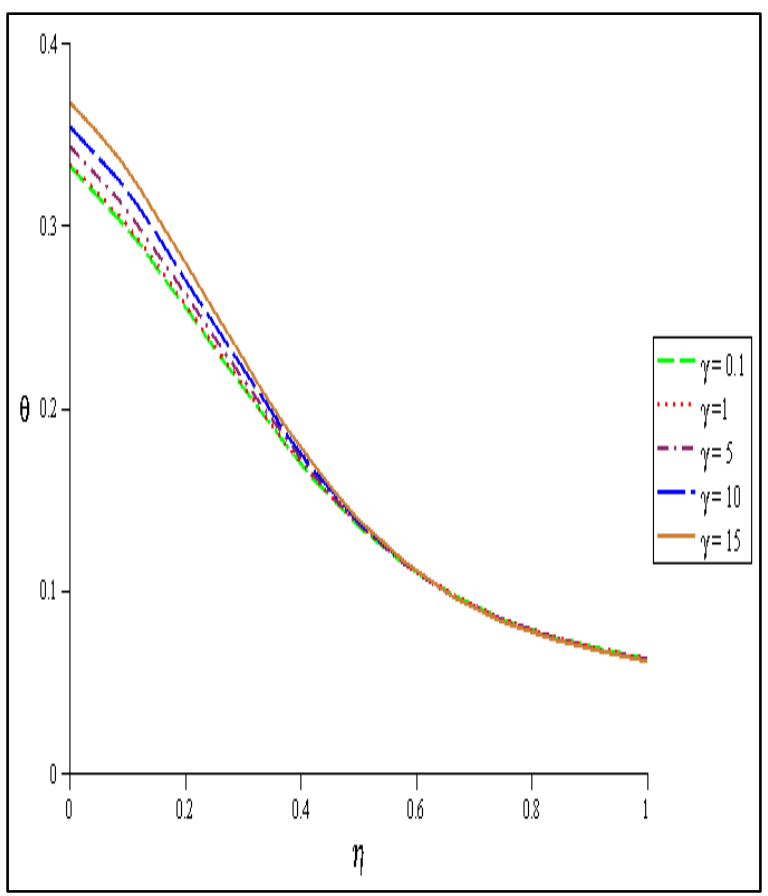

Figure 10. Temperature profiles for different values of $\gamma$.

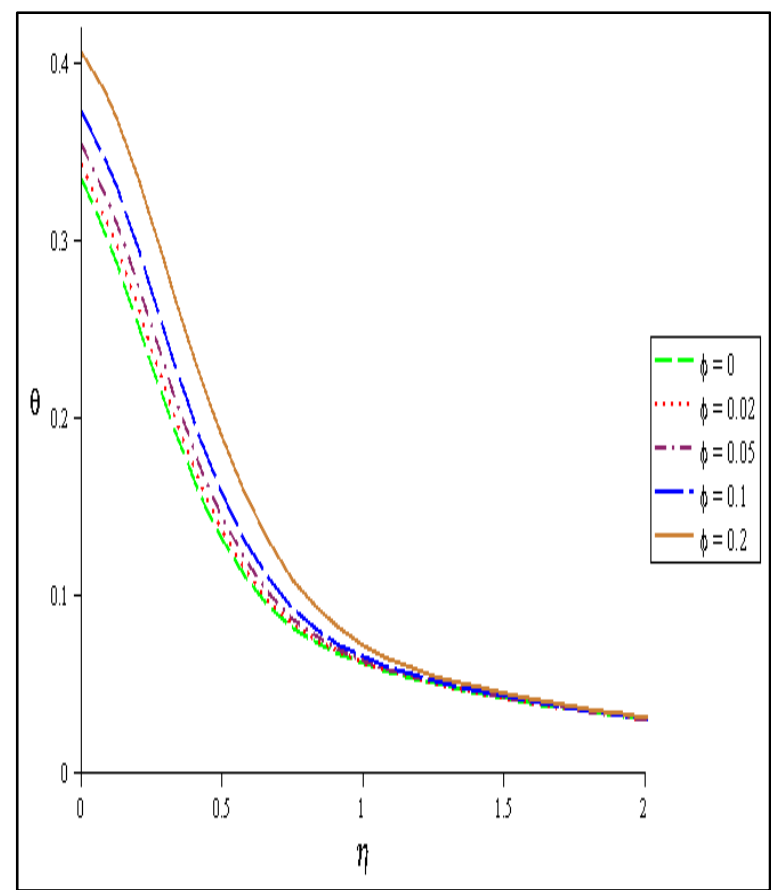

Figure 9. Temperature profiles for different values of $\varphi$.

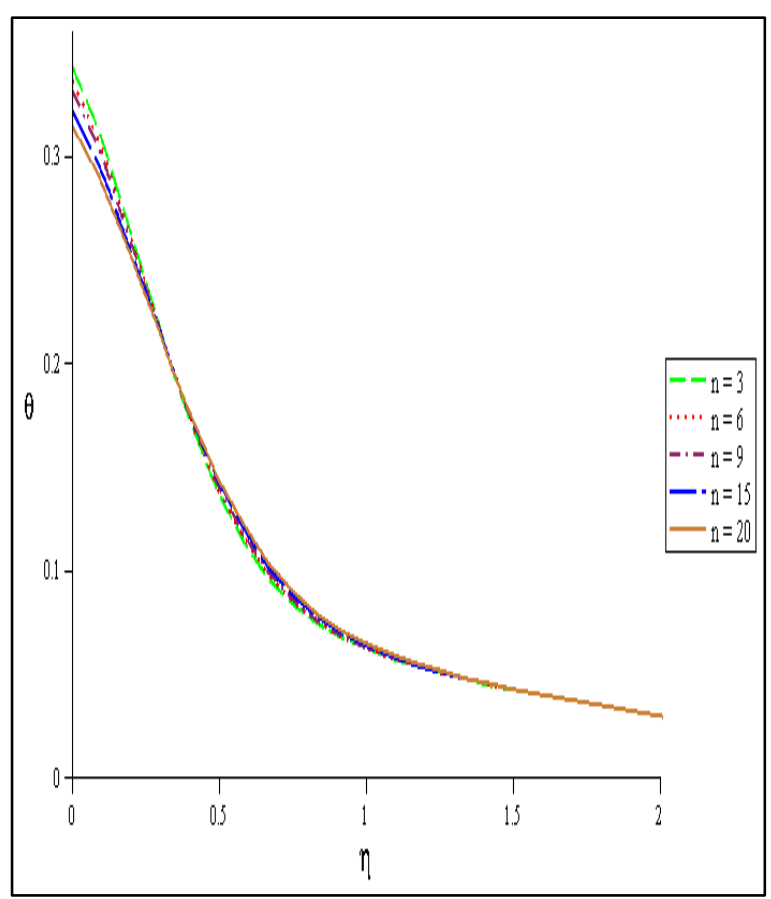

Figure 11. Temperature profiles for different values of $n$. 


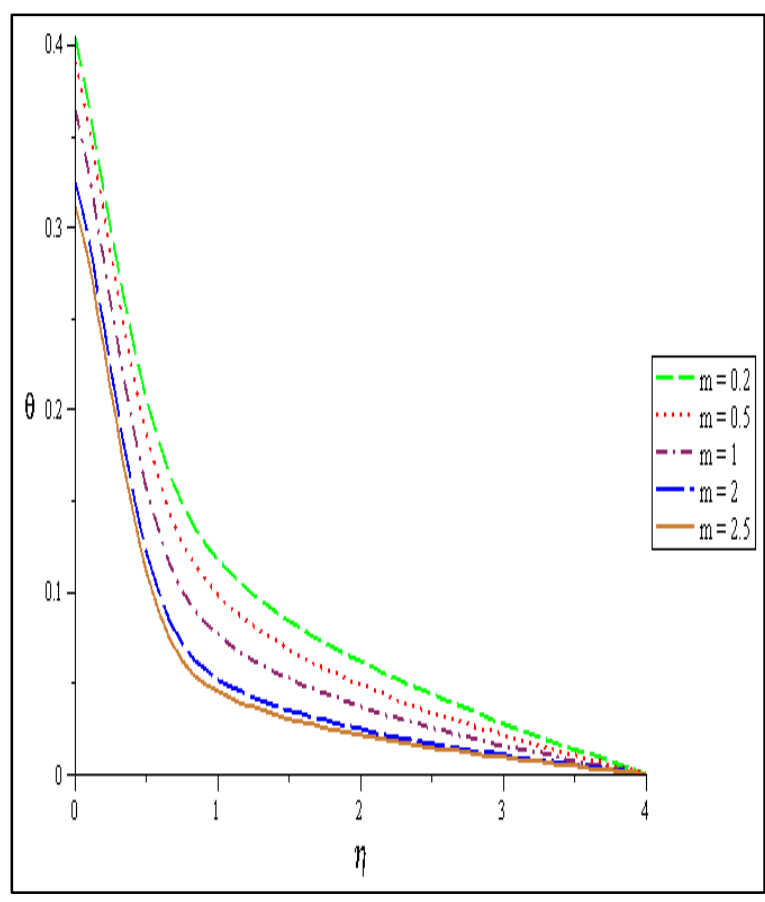

Figure 12. Temperature profiles for different values of $m$.

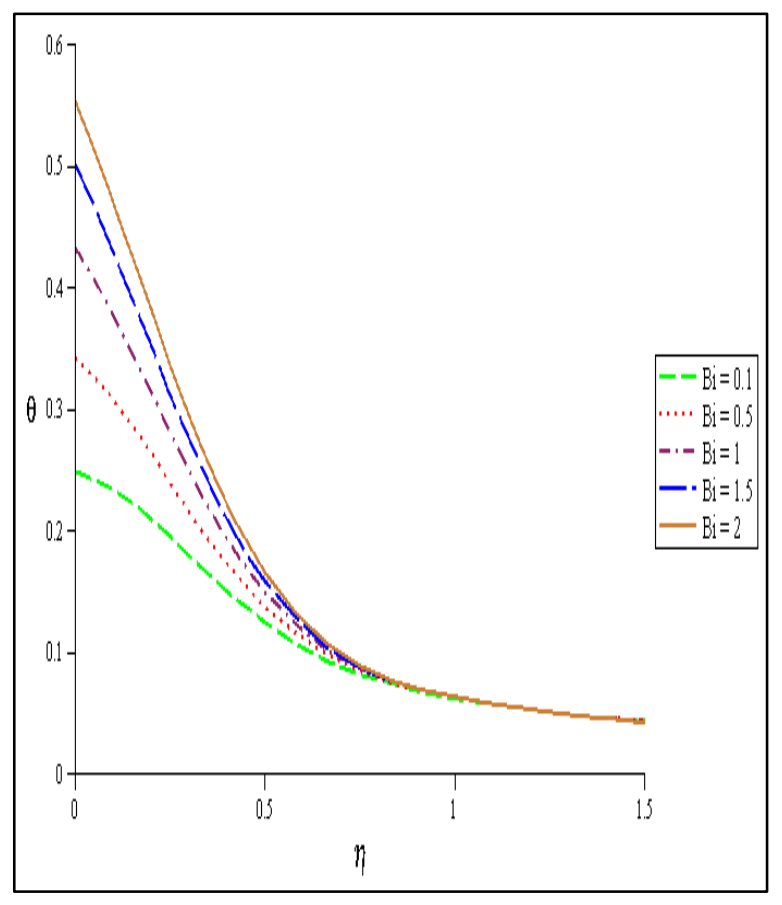

Figure 13. Temperature profiles for different values of $\mathrm{Bi}$.

The effect of the Biot number (or surface convection parameter) $B i=0.1,0.5,1,1.5$, and 2 on the temperature profiles against $\eta$ is displayed in Figure 13. From this figure, we notice that the temperature profiles within the boundary layer increase with the increase of the Biot number. The surface convection parameter (or Biot number) is a ratio of the hot fluid side convection resistance to the cold fluid side convection resistance on a surface. For fixed cold fluid properties and fixed free stream velocity, the surface convection parameter is proportional to the heat transfer coefficient $h$ associated with the hot fluid. The thermal resistance on the hot fluid side is inversely proportional to $h$. We further notice that throughout the boundary layer the temperature profiles decrease monotonically with the increase of $\eta$. From this figure it is also noticed that for large values of $B i$, i.e. $B i \rightarrow \infty$, the temperature profile attains its maximum value of 1 . It is important to note that we observed a negligible effect of the Biot number on the velocity profiles. This is due to the fact, as can be seen from equation (26), that $B i$ appears only in the thermal boundary conditions and thus has a negligible effect on fluid velocity.

\subsection{Effect of base fluids and nanoparticles}

Here we investigate the effects of different base fluids and nanoparticles on the flow and temperature fields, as can be seen from Figures 14 to 20 . Figure 14 presents velocity profiles considering aluminium oxide nanoparticles $\left(\mathrm{Al}_{2} \mathrm{O}_{3}\right)$ with different base fluids (water, engine oil, and ethylene glycol) within the boundary layer. In this figure, we notice that variation in the base fluids has no significant effect on the velocity profiles, but it can clearly be seen from a magnified part of the curve that ethylene glycol- $\mathrm{Al}_{2} \mathrm{O}_{3}$ nanofluid has the lowest value of velocity while water- $\mathrm{Al}_{2} \mathrm{O}_{3}$ nanofluid has the highest value of velocity, followed by engine oil. A similar result is also noticed for various base fluids considering $\mathrm{Cu}$ and $\mathrm{TiO}_{2}$ nanoparticles, as depicted in Figures 15 and 16.

The effects of different base fluids and nanoparticles on temperature profiles are shown in Figures 17 to 19. Figure 17 shows how base fluids with $\mathrm{Al}_{2} \mathrm{O}_{3}$ nanoparticles affect the temperature profiles. It is clearly seen that the temperature of engine oil- $\mathrm{Al}_{2} \mathrm{O}_{3}$ nanofluid is higher than those of the water- $\mathrm{Al}_{2} \mathrm{O}_{3}$ and ethylene glycol- $\mathrm{Al}_{2} \mathrm{O}_{3}$ nanofluids in the vicinity of the surface. This is due to the high Prandtl number of engine oil, which means the molecules of engine oil absorb more heat from the surface of the sheet compared with the other base fluids. This phenomenon is true for the limiting value of $\eta$ in which $\eta \leq 0.1$. For $\eta \geq 0.1$, the behavior of the temperature profiles is reversed. We further notice that the thickness of the thermal boundary layer is lower when the base fluid is water. In Figures 18 to 19 we present temperature profiles in different base fluids considering $\mathrm{Cu}$ and $\mathrm{TiO}_{2}$ nanoparticles. Similar patterns are observed for $\mathrm{Cu}$ and $\mathrm{TiO}_{2}$ nanoparticles as for $\mathrm{Al}_{2} \mathrm{O}_{3}$ nanoparticles in various base fluids. From these figures we may conclude that a base fluid having a high Prandtl number absorbs more heat from the surface of the sheet.

Figures 20 and 21 show the comparison between the effects of $\mathrm{Cu}$ and $\mathrm{Al}_{2} \mathrm{O}_{3}$ nanoparticles, using different base fluids on the velocity and temperature profiles when $\varphi=0.02, B i=0.5, \gamma=5, H a=0.5$, and $E c=0.05$. In Figure 20, we observe that a nanofluid containing $\mathrm{Cu}$ nanoparticles has higher velocity than a nanofluid having $\mathrm{Al}_{2} \mathrm{O}_{3}$ nanoparticles. From Figure 21 we notice that nanofluids with $C u$ nanoparticles show higher temperature than the nanofluids having $\mathrm{Al}_{2} \mathrm{O}_{3}$ nanoparticles. 


\subsection{Computational results for rate of heat transfer and shear stress}

The variation of rate of heat transfer in terms of Nusselt number and rate of shearing in terms of skin friction coefficient in three types of base fluids for different solid nanoparticles are displayed in the Figures 22 to 39 , to investigate the effects of the physical parameters $m, \alpha, B i$, and Pr on them.

\subsubsection{The Nusselt number}

\subsubsection{Nusselt number in different base fluids with $\mathrm{Cu}$ nanoparticles}

The influence of the nonlinear stretching index $m$ on the Nusselt number considering $\mathrm{Cu}-\mathrm{H}_{2} \mathrm{O}, \mathrm{Cu}-\mathrm{EG}, \mathrm{Cu}-\mathrm{EO}$ nanofluids for different values of nanoparticle volume fraction $\varphi$ is shown in Figure 22. It can be noticed that the rate of heat transfer in the water-based nanofluids is higher than those of the ethylene glycol and engine oil based nanofluids for all variations of the stretching index $m$. It is also clear that the rate of heat transfer in $\mathrm{Cu}-\mathrm{H}_{2} \mathrm{O}$ nanofluid increases with the increase of the stretching index $m$, whereas it decreases in the $C u$-EG, and $C u$-EO nanofluids with the increase of $m$.

In Figure 23 we have presented the Nusselt number against $\varphi$ for the $\mathrm{Cu}-\mathrm{H}_{2} \mathrm{O}$ nanofluid for different values of the angle of inclination $\alpha$, keeping all other parameter values fixed. Figure 23 reveals the effect of the angle of inclination on the Nusselt number, i.e. an increase in the value of $\alpha$ produces a decrease in the Nusselt number.

Figure 24 shows that the rate of heat transfer from the surface of the sheet to the fluid in $\mathrm{Cu}$-water nanofluid increases with the increase of the Biot number $B i$. It is also noted that the rate of heat transfer increases with the increase of the nanoparticles volume fraction $\varphi$ when Biot number $B i \geq 1$, whereas it decreases when $B i<1$.Thus, the addition of nanofluid to the base fluid may not always increase the rate of heat transfer. In $C u$-ethylene glycol $(E G)$ nanofluid the rate of heat transfer decreases for all increasing values of the stretching index as well as for the increase of the nanoparticles volume fraction, as can be seen from Figure 25. Therefore, the rate of heat transfer significantly depends on the base fluids as well as on the surface convection parameter.

The Nusselt number versus the nanoparticles volume fraction $\varphi$ is plotted in Figure 26 for several values of the Biot number $\mathrm{Bi}$, considering $\mathrm{Cu}$-engine oil $(E O)$ nanofluid. From this figure it is observed that the value of the Nusselt number increases with the increase of the Biot number when $0 \leq \varphi \leq 0.03$. Beyond this range of $\varphi$, the behavior of heat transfer changes, in that the Nusselt number decreases with the increase of the Biot number. Thus, addition of nanoparticles to the base fluid may not always increase the rate of heat transfer. It significantly depends on the Biot number.

The effects of the different values of the inclination angle $\alpha$ and Biot number $B i$ on the Nusselt number for $C u$ $\mathrm{H}_{2} \mathrm{O}, \mathrm{Cu}-\mathrm{EG}$, and $\mathrm{Cu}-\mathrm{EO}$ nanofluids are presented in Figures 27 to 28, respectively. From Figure 27, it is clear that the water-based nanofluids have a higher value of Nusselt number than the ethylene glycol and engine oil based nanofluids for all variations of the angle of inclination $\alpha$. This phenomenon might be caused by features of the base fluid; for example, water has a lower value of Prandtl number than the engine oil and ethylene glycol. In addition, the hydrogen bond in a hydrocarbon (engine oil and ethylene glycol) is much weaker than the hydrogen bond in water. In Figure 28 we compare the Nusselt number in different base fluids, considering $C u$ as nanoparticles and varying $B i$ and $\varphi$. This figure shows that heat transfer in nanofluid not only depends on the base fluids and nanoparticles, but significantly on the surface convection too.

\subsubsection{Nusselt number for water based nanofluids}

The comparisons between the Nusselt numbers for water-based nanofluids such as $\mathrm{Cu}-\mathrm{H}_{2} \mathrm{O}, \mathrm{TiO}_{2}-\mathrm{H}_{2} \mathrm{O}$, and $\mathrm{Al}_{2} \mathrm{O}_{3}-\mathrm{H}_{2} \mathrm{O}$ for various values of $\mathrm{m}, \mathrm{Bi}$ and $\alpha$ are presented in Figures 29 to 33, respectively. It is found that the Nusselt number increases with the increase of the stretching index for all types of nanoparticles as shown in Figure 29. It is also found that $\mathrm{Al}_{2} \mathrm{O}_{3}-\mathrm{H}_{2} \mathrm{O}$ nanofluid provides the highest rate of heat transfer.

Figure 30 shows that change in the Nusselt number is higher for large values of the Biot number $\mathrm{Bi}$. It is observed that for fixed values of $\mathrm{Bi}$ and $\varphi$ the $\mathrm{Cu}-\mathrm{H}_{2} \mathrm{O}$ nanofluid has the lowest value of Nusselt number, while $\mathrm{Al}_{2} \mathrm{O}_{3}-\mathrm{H}_{2} \mathrm{O}$ nanofluid has the highest value of Nusselt number, followed by $\mathrm{TiO}_{2}-\mathrm{H}_{2} \mathrm{O}$ nanofluid. From Figure 31 it is found that the Nusselt number decreases with the increase of the value of angle of inclination for different kinds of nanofluids.

\subsubsection{Nusselt number in different base fluids with different nanoparticles}

The variations of Nusselt numbers in different base fluids with different nanoparticles for various values of $\varphi$ and $B i=0.5,1.0,2.0$ are shown in Figures 32 to 34, respectively. These figures clearly indicate that large values of $B i$ (when the external thermal resistance of the surface is lower than the internal thermal resistance) may significantly change the heat transfer characteristics of a nanofluid. In Figure 34 we notice that for $\varphi<\varphi_{\text {crit }}$, ethylene glycol-based nanofluids have higher values of Nusselt number than those of water and engine oil based nanofluids. Outside this range of $\varphi$ (i.e. $\varphi \geq \varphi_{\text {crit }}$ ), the behavior of the Nusselt number is similar to the cases of $B i=0.5$ and $B i=1$. 


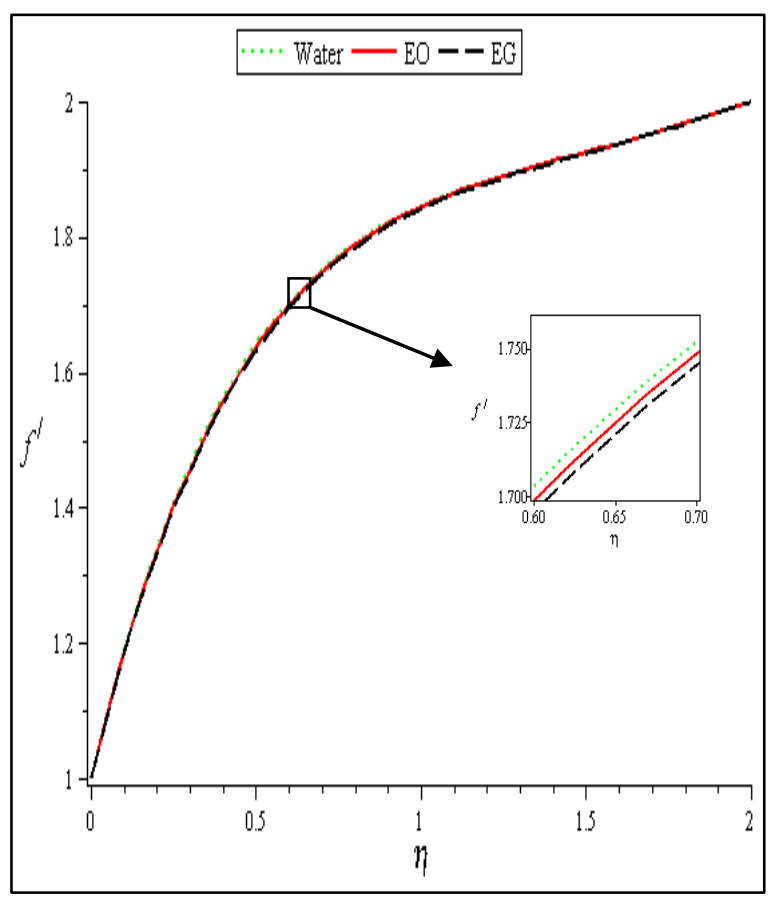

Figure 14. Velocity profiles in different base fluids with $\mathrm{Al}_{2} \mathrm{O}_{3}$ nanoparticles.

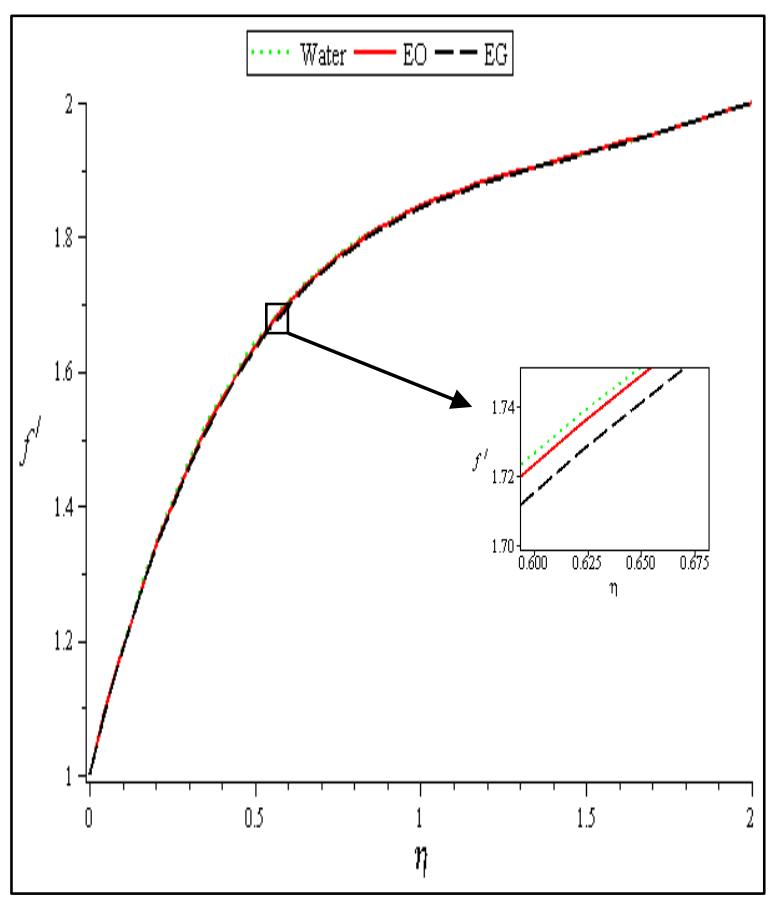

Figure 16. Velocity profiles in different base fluids with $\mathrm{TiO}_{2}$ nanoparticles.

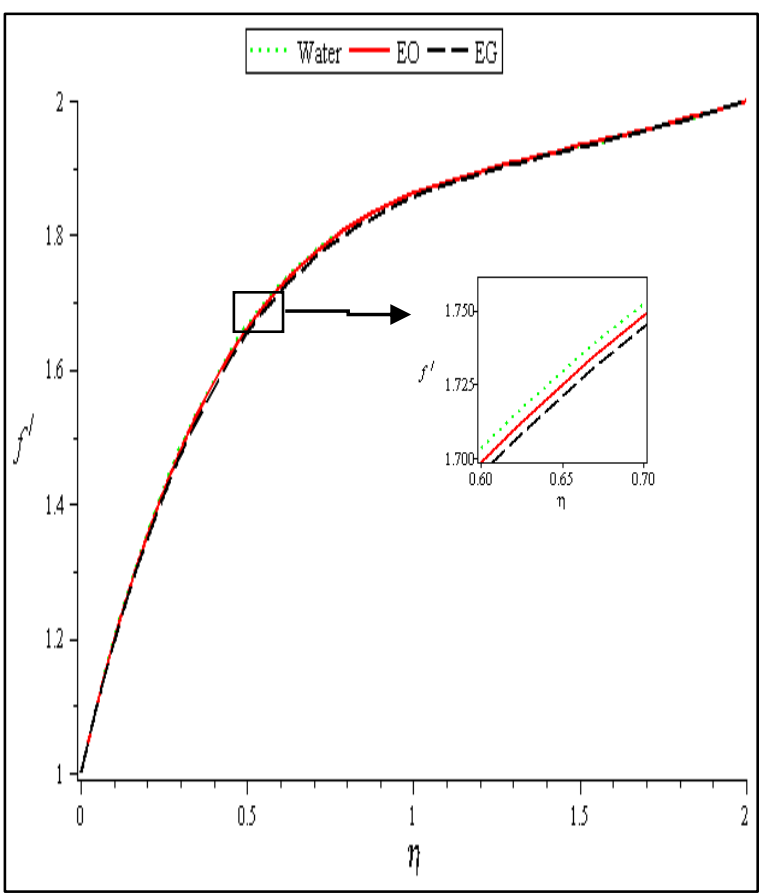

Figure 15. Velocity profiles in different base fluids with $\mathrm{Cu}$ nanoparticles.

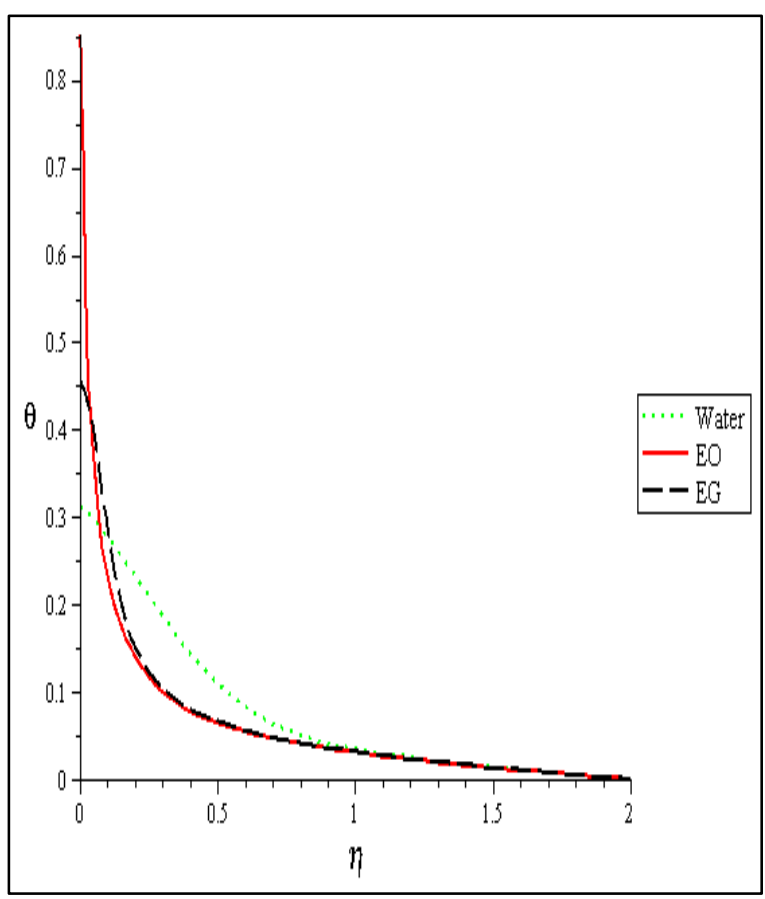

Figure 17. Temperature profiles in different base fluids with $\mathrm{Al}_{2} \mathrm{O}_{3}$ nanoparticles. 


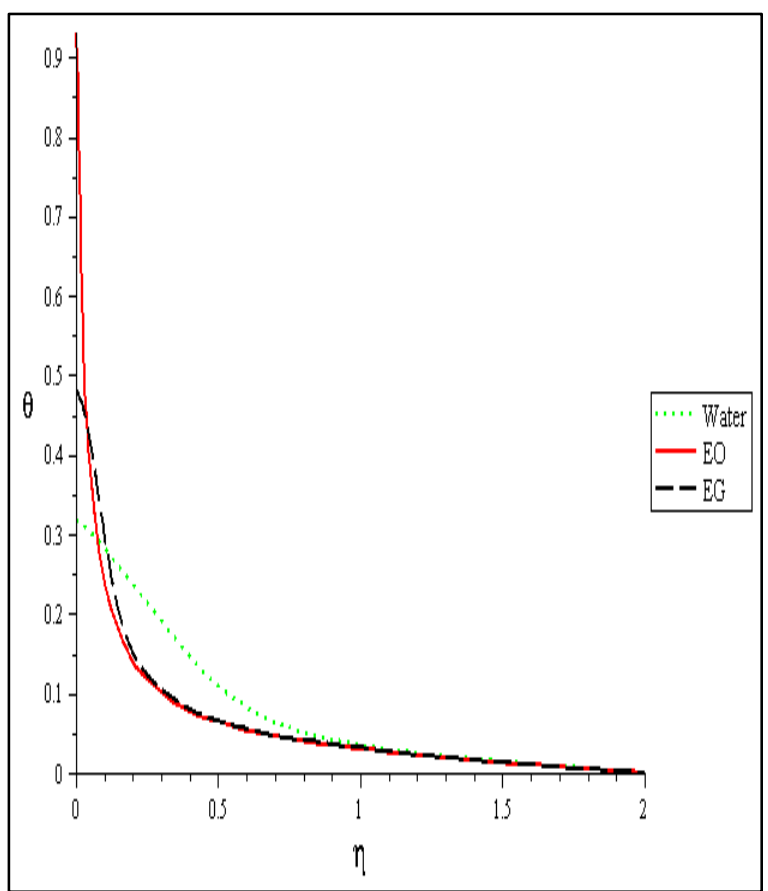

Figure 18. Temperature profiles in different base fluids with $C u$ nanoparticles.

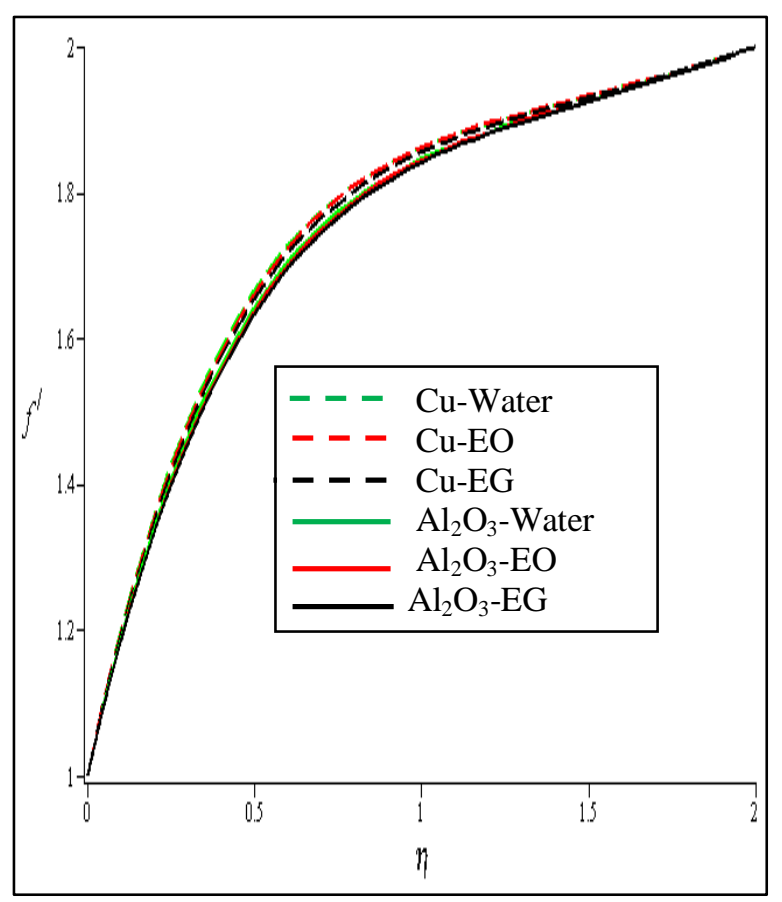

Figure 20. Velocity profiles for comparison between $\mathrm{Cu}$ and $\mathrm{Al}_{2} \mathrm{O}_{3}$ nanoparticles in different base fluids.

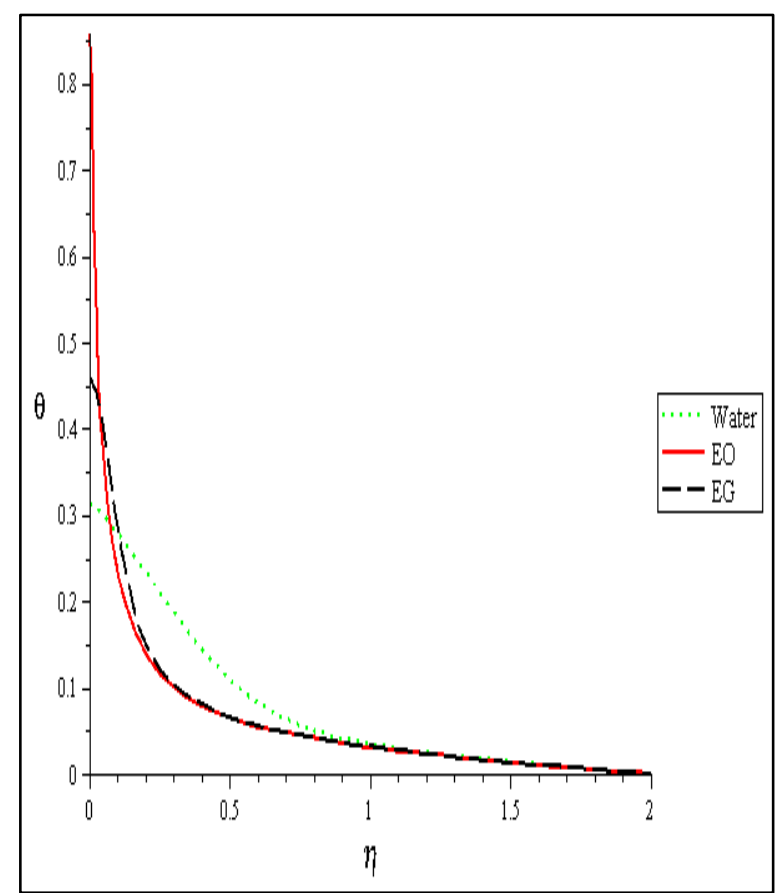

Figure 19. Temperature profiles in different base fluids with $\mathrm{TiO}_{2}$ nanoparticles.

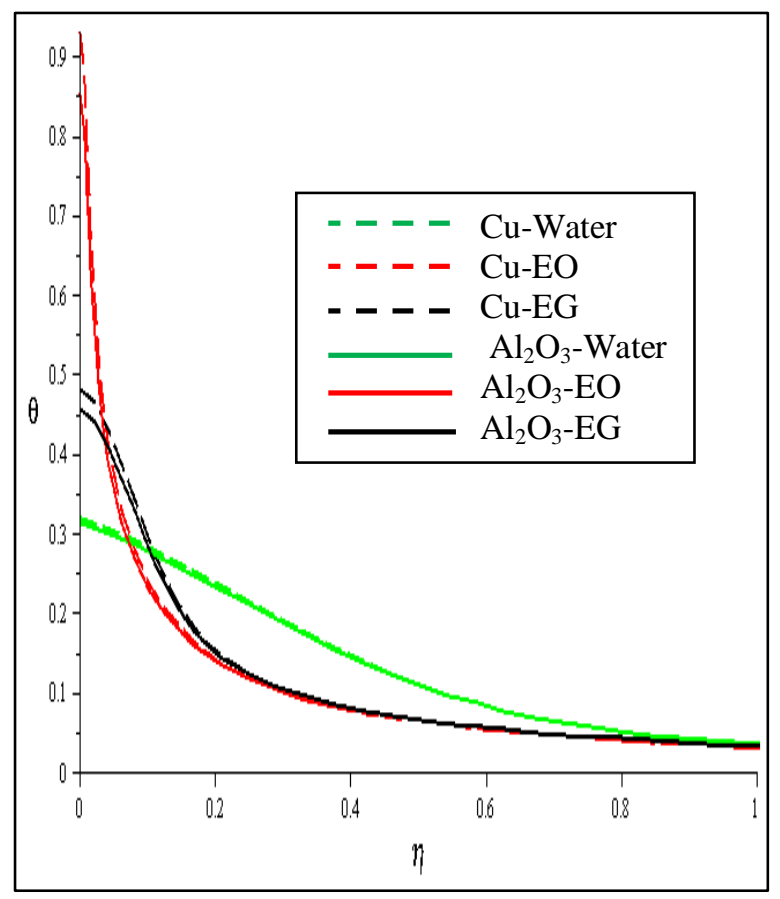

Figure 21. Temperature profiles for comparison between $\mathrm{Cu}$ and $\mathrm{Al}_{2} \mathrm{O}_{3}$ nanoparticles in different base fluids. 


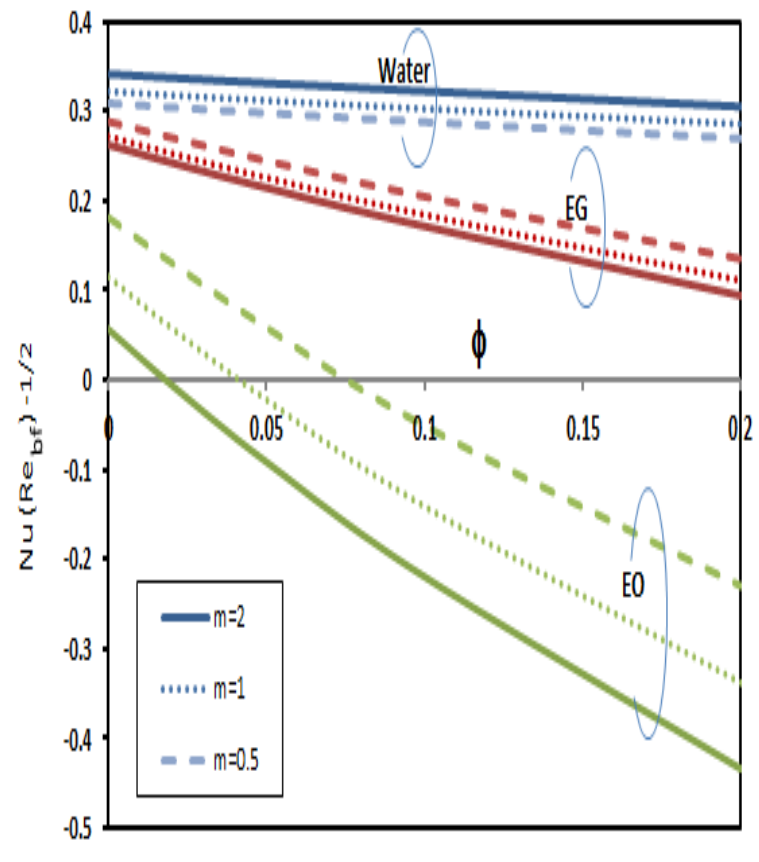

Figure 22. Nusselt number for different values of $m$ and $\varphi$ in $\mathrm{Cu}-\mathrm{H}_{2} \mathrm{O}, \mathrm{Cu}-\mathrm{EG}, \mathrm{Cu}-\mathrm{EO}$ nanofluids.

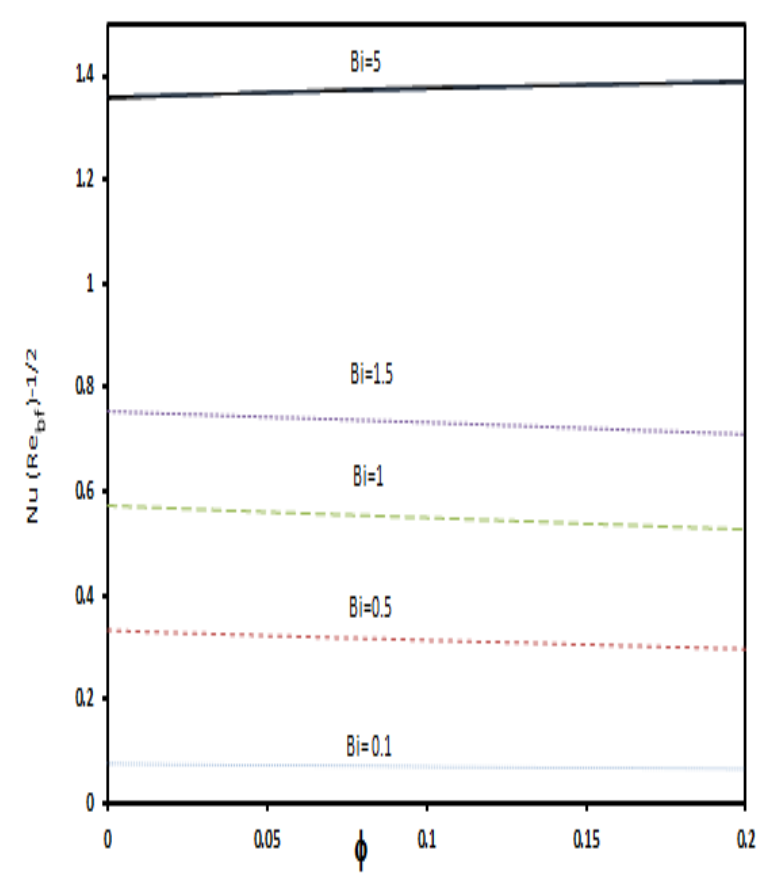

Figure 24. Nusselt number for different values of $B i$ and $\varphi$ for $\mathrm{Cu}-\mathrm{H}_{2} \mathrm{O}$ nanofluid.

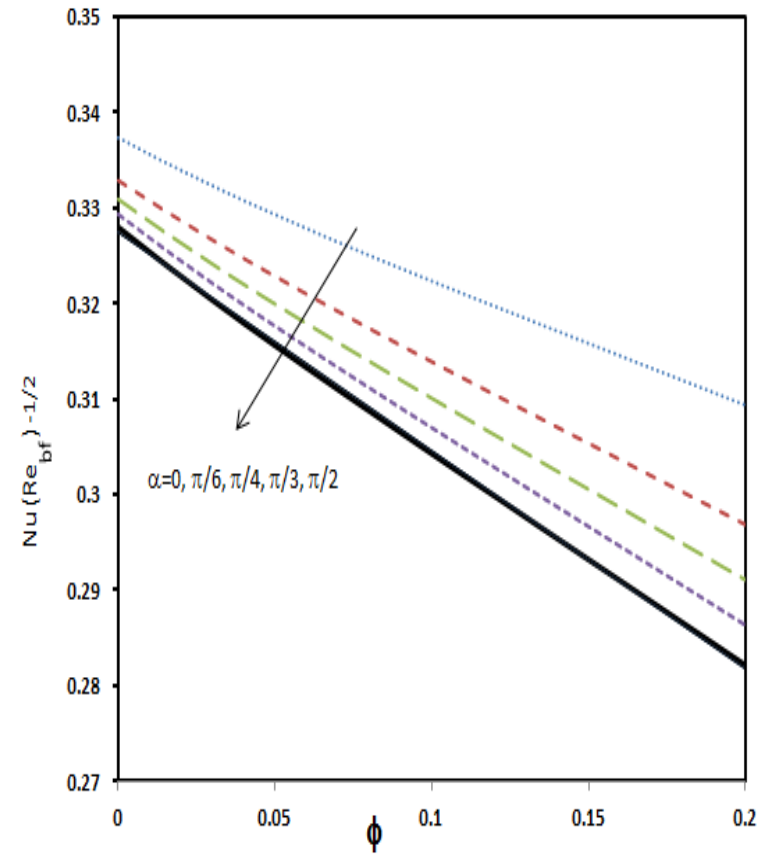

Figure 23. Nusselt number for different values of $\alpha$ and $\varphi$ for $\mathrm{Cu}-\mathrm{H}_{2} \mathrm{O}$ nanofluid.

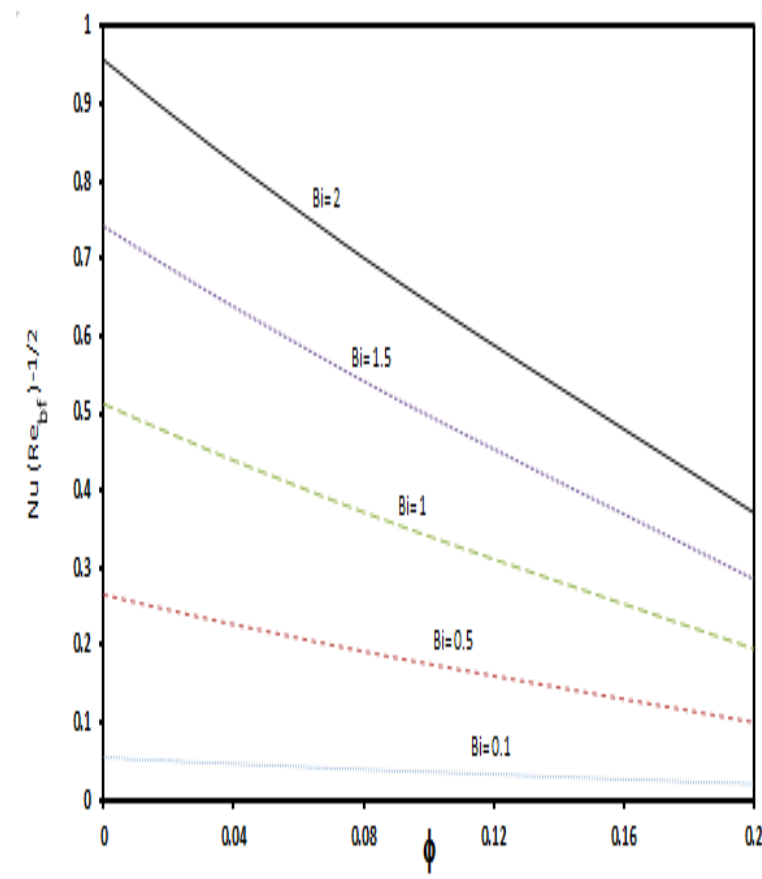

Figure 25. Nusselt number for different values of $B i$ and $\varphi$ for $C u-E G$ nanofluid. 


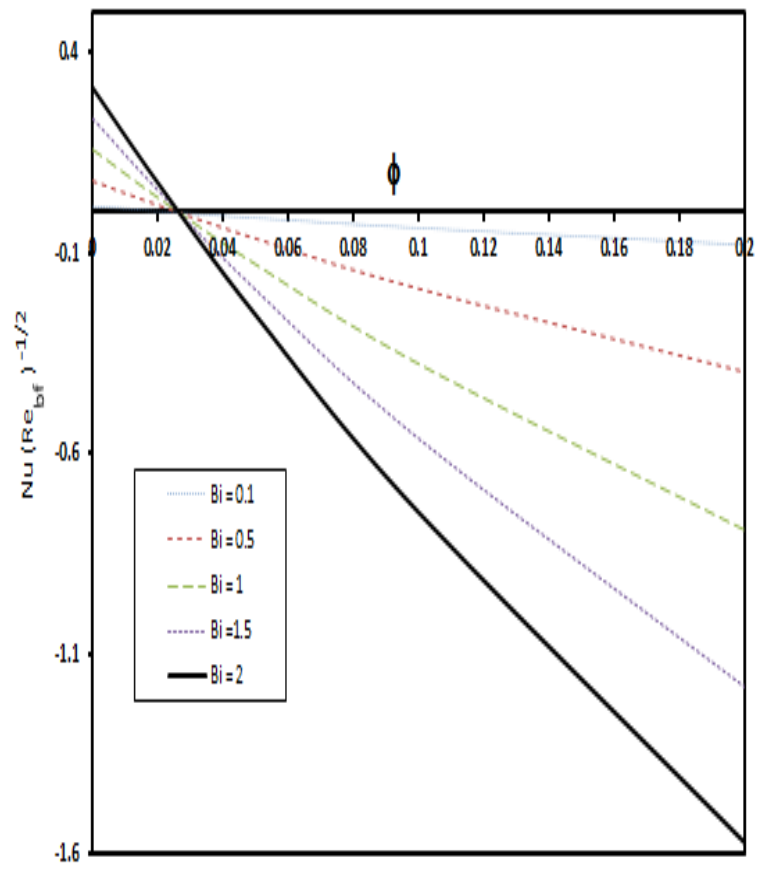

Figure 26. Nusselt number for different values of $B i$ and $\varphi$ for $C u$-EO nanofluid.

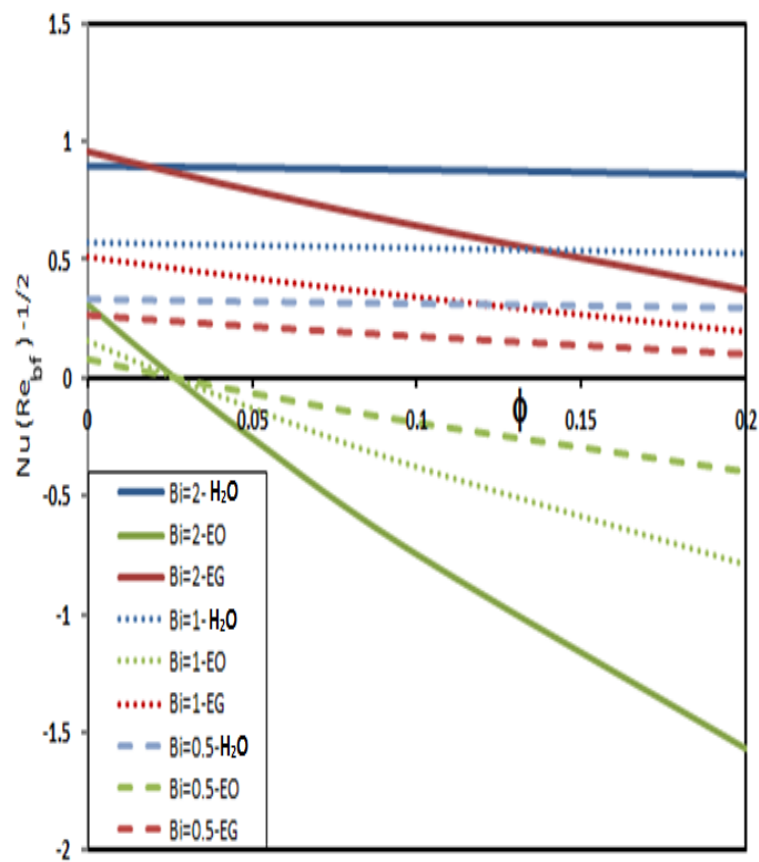

Figure 28. Nusselt number for different values of $B i$ and $\varphi$ in $\mathrm{Cu}-\mathrm{H}_{2} \mathrm{O}, \mathrm{Cu}-\mathrm{EG}$, and $\mathrm{Cu}-\mathrm{EO}$ nanofluids.

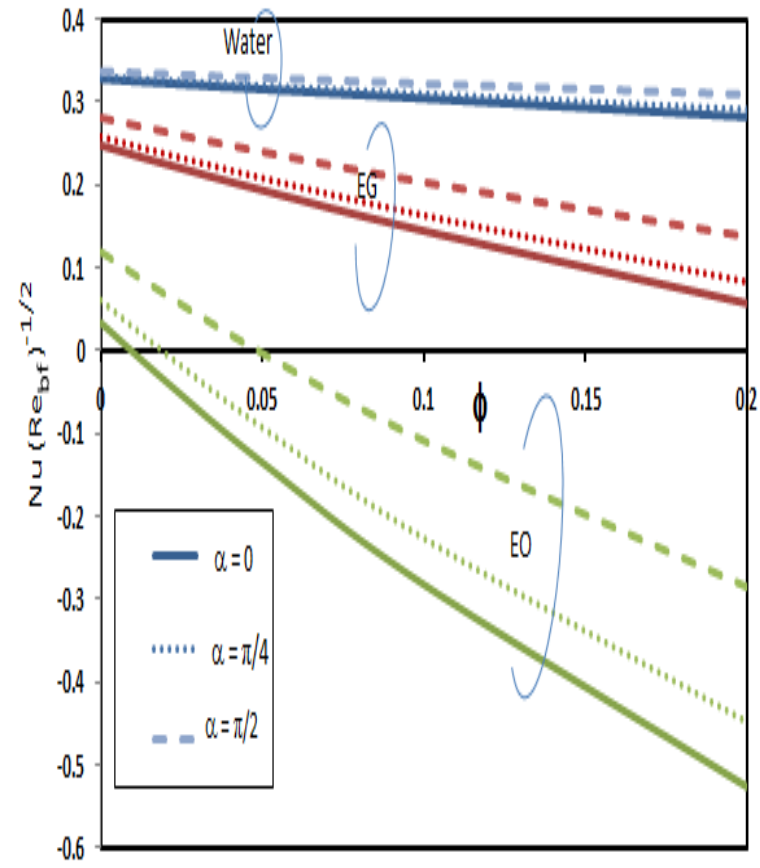

Figure 27. Nusselt number for different values of $\alpha$ and $\varphi$ in $\mathrm{Cu}-\mathrm{H}_{2} \mathrm{O}, \mathrm{Cu}-\mathrm{EG}$, and $\mathrm{Cu}-\mathrm{EO}$ nanofluids.

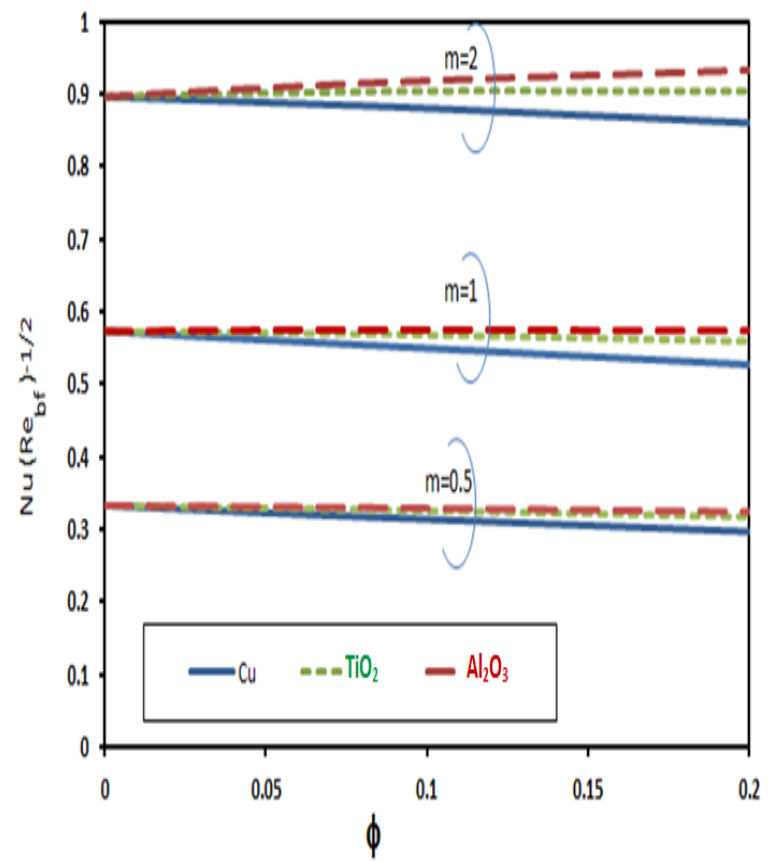

Figure 29. Nusselt number for different values of $m$ and $\varphi$ in $\mathrm{Cu}-\mathrm{H}_{2} \mathrm{O}, \mathrm{TiO}_{2}-\mathrm{H}_{2} \mathrm{O}$, and $\mathrm{Al}_{2} \mathrm{O}_{3}-\mathrm{H}_{2} \mathrm{O}$ nanofluids. 


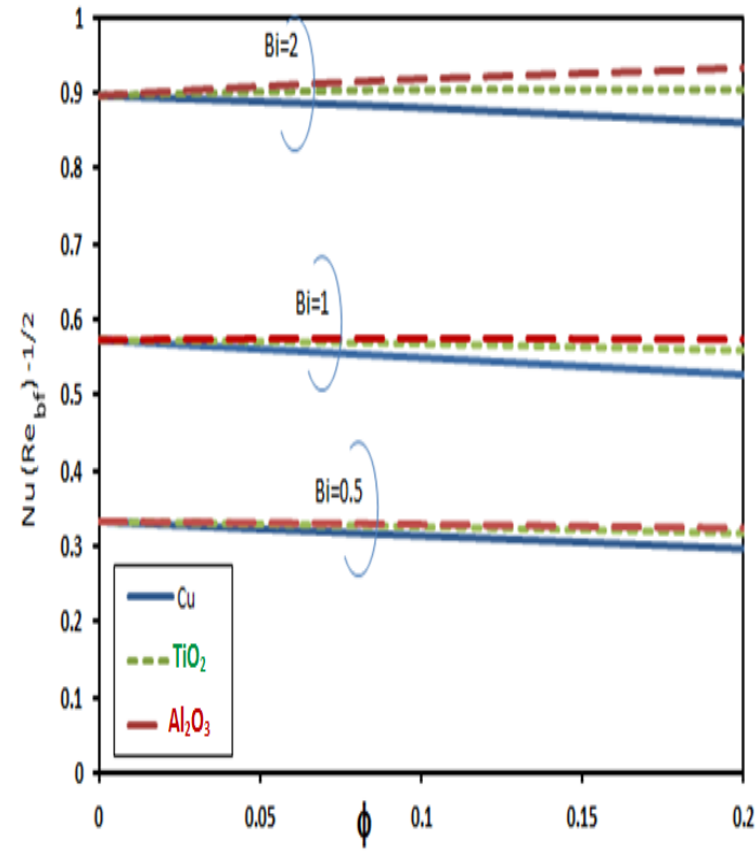

Figure 30. Nusselt number for different values of $B i$ and $\varphi$ in $\mathrm{Cu}-\mathrm{H}_{2} \mathrm{O}, \mathrm{TiO}_{2}-\mathrm{H}_{2} \mathrm{O}, \mathrm{Al}_{2} \mathrm{O}_{3}-\mathrm{H}_{2} \mathrm{O}$ nanofluids.

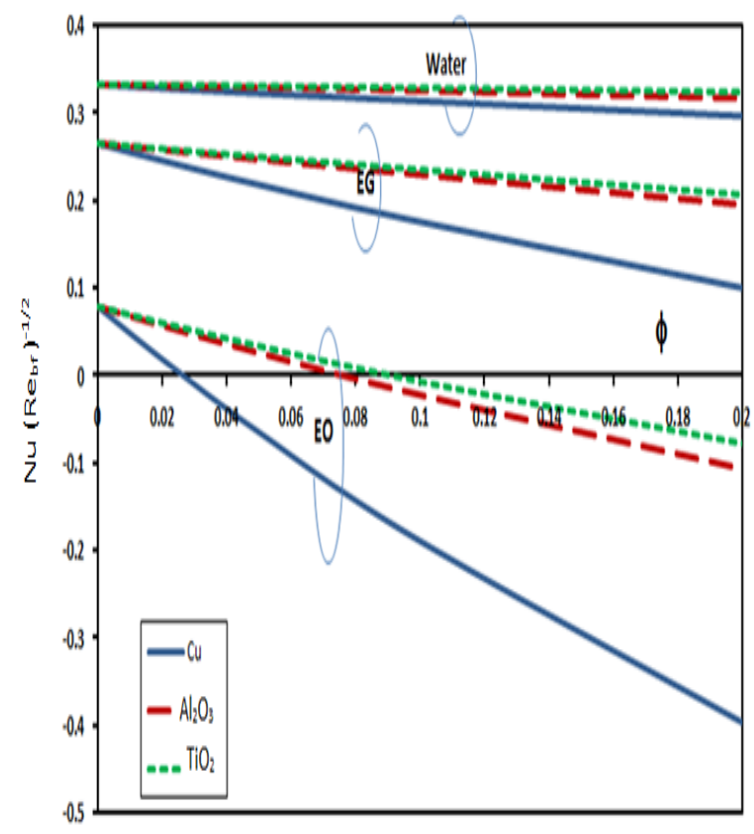

Figure 32. Nusselt number for different base fluids using different nanoparticles when $B i=0.5$.

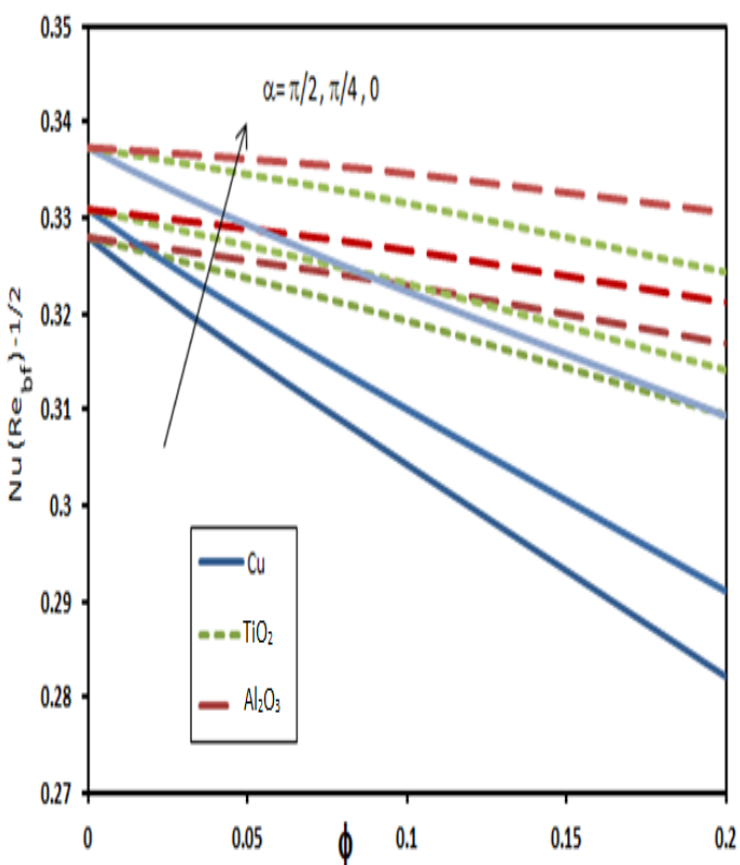

Figure 31. Nusselt number for different values of $\alpha$ and $\varphi$ in $\mathrm{Cu}-\mathrm{H}_{2} \mathrm{O}, \mathrm{TiO}_{2}-\mathrm{H}_{2} \mathrm{O}, \mathrm{Al}_{2} \mathrm{O}_{3}-\mathrm{H}_{2} \mathrm{O}$ nanofluids.

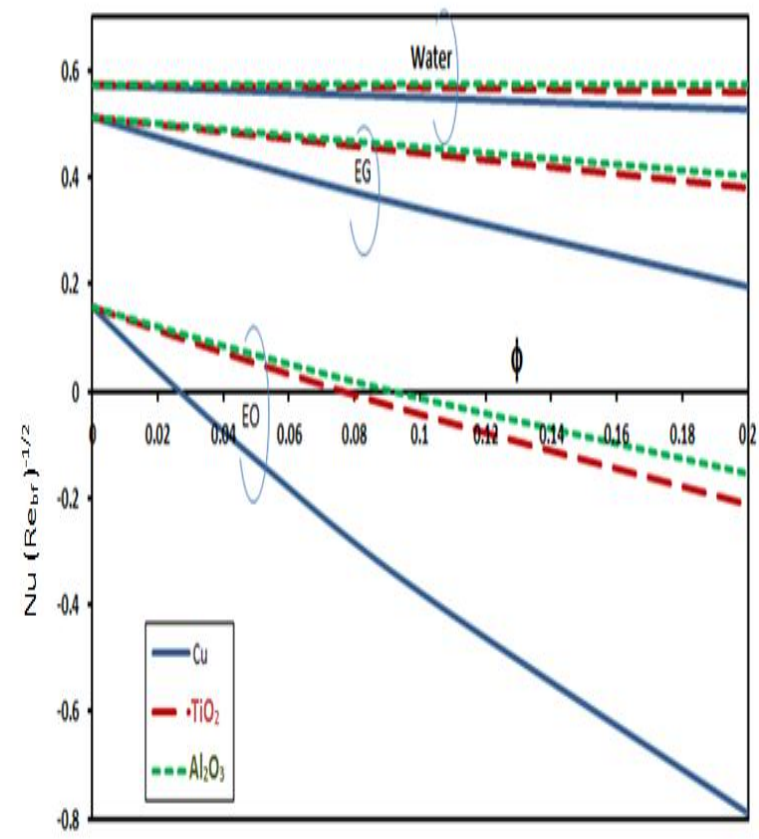

Figure 33. Nusselt number for different base fluids using different nanoparticles when $B i=1$. 


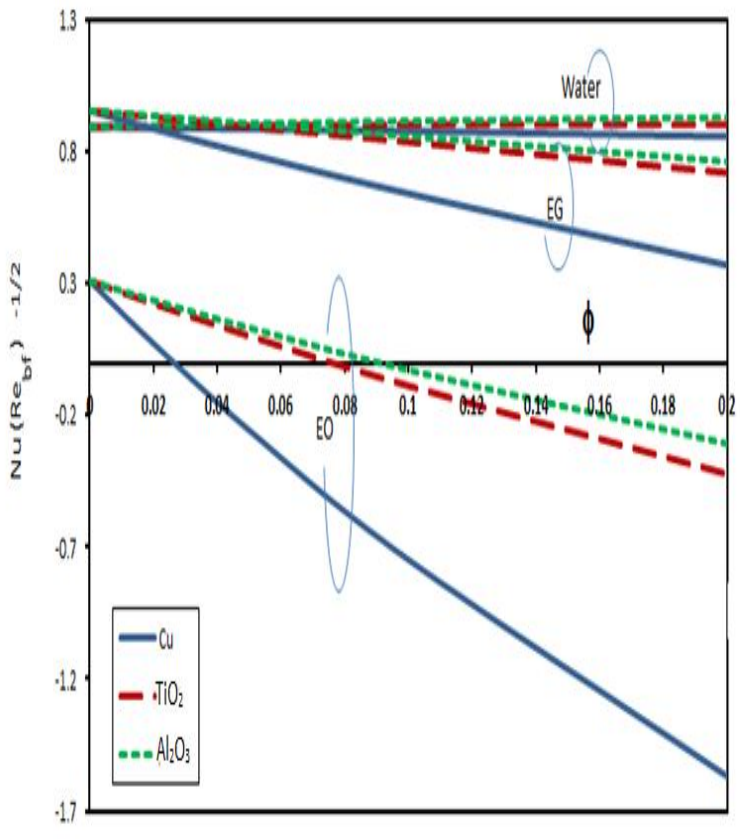

Figure 34. Nusselt number for different base fluids using different nanoparticles when $B i=2$.

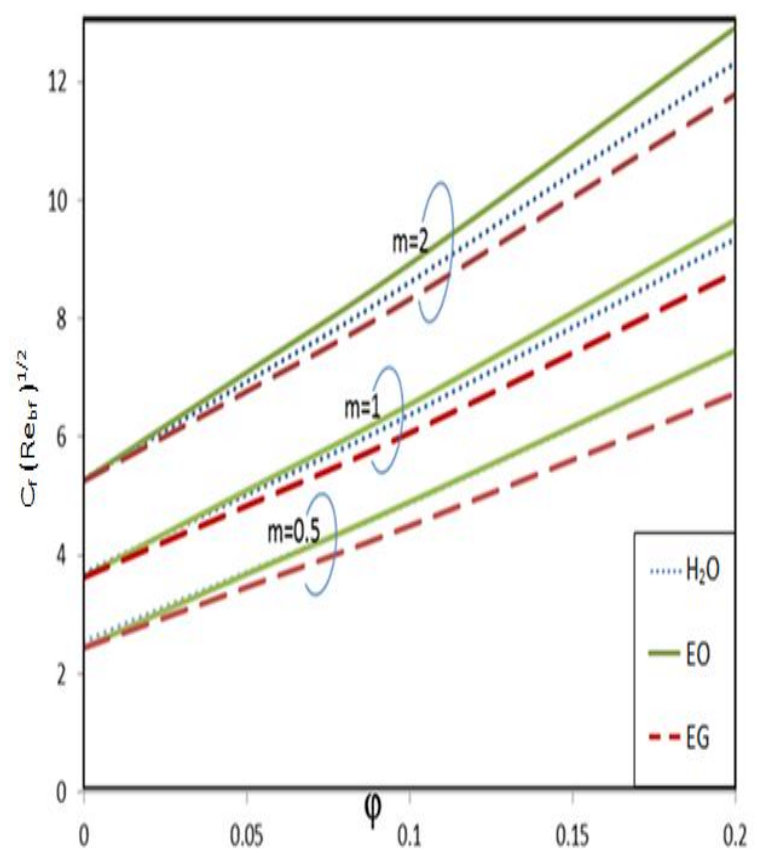

Figure 36. Skin-friction coefficient for different base fluids using $C u$ nanoparticles for different values of $m$.

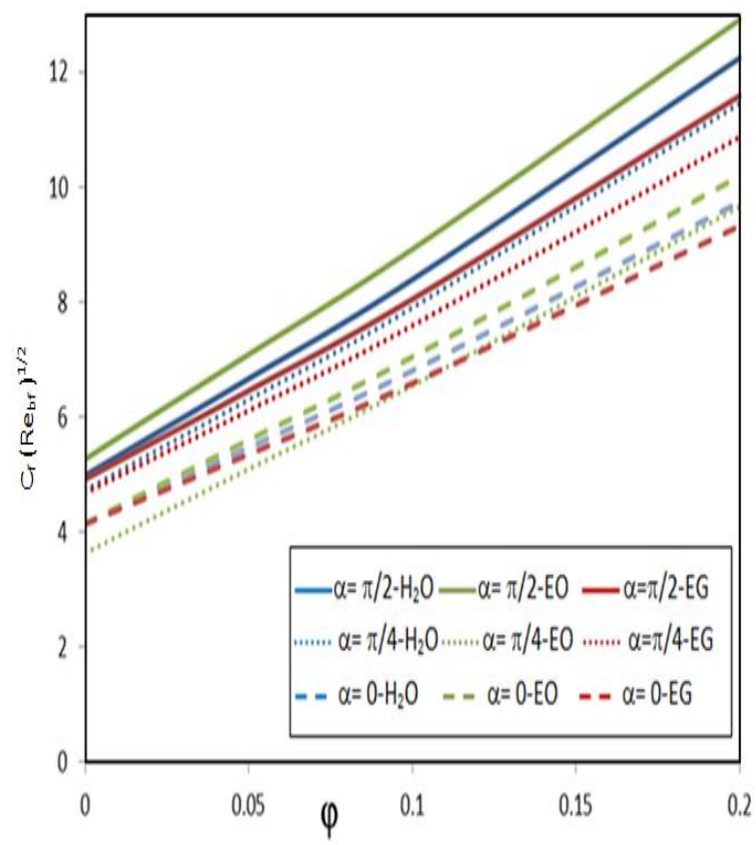

Figure 35. Skin-friction coefficient for different base fluids using $C u$ nanoparticles for different values of $\alpha$.

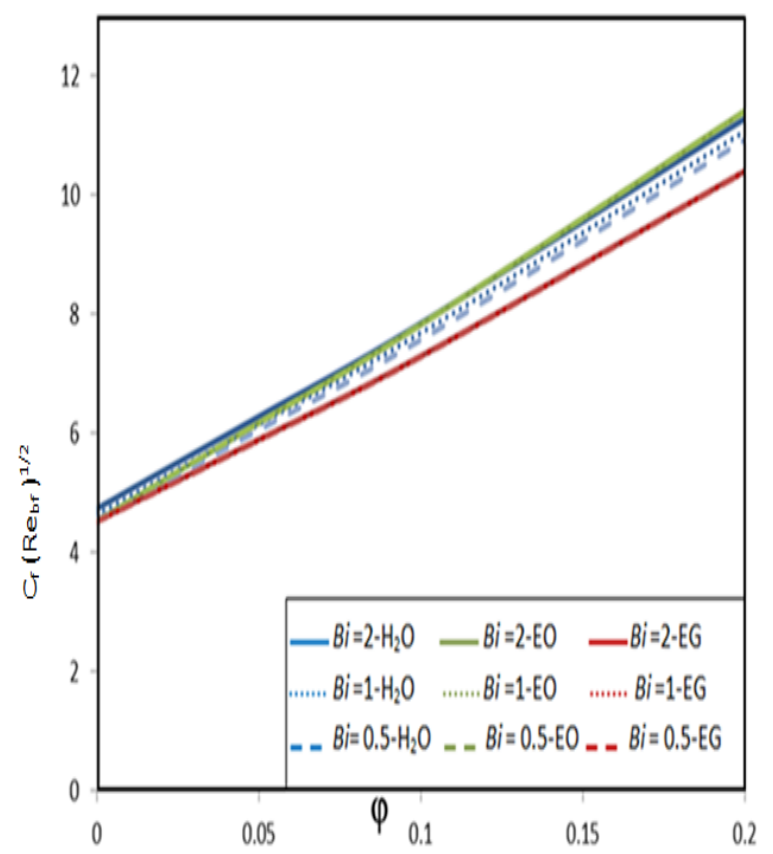

Figure 37. Skin-friction coefficient for different base fluids using $C u$ nanoparticles for different values of Bi. 


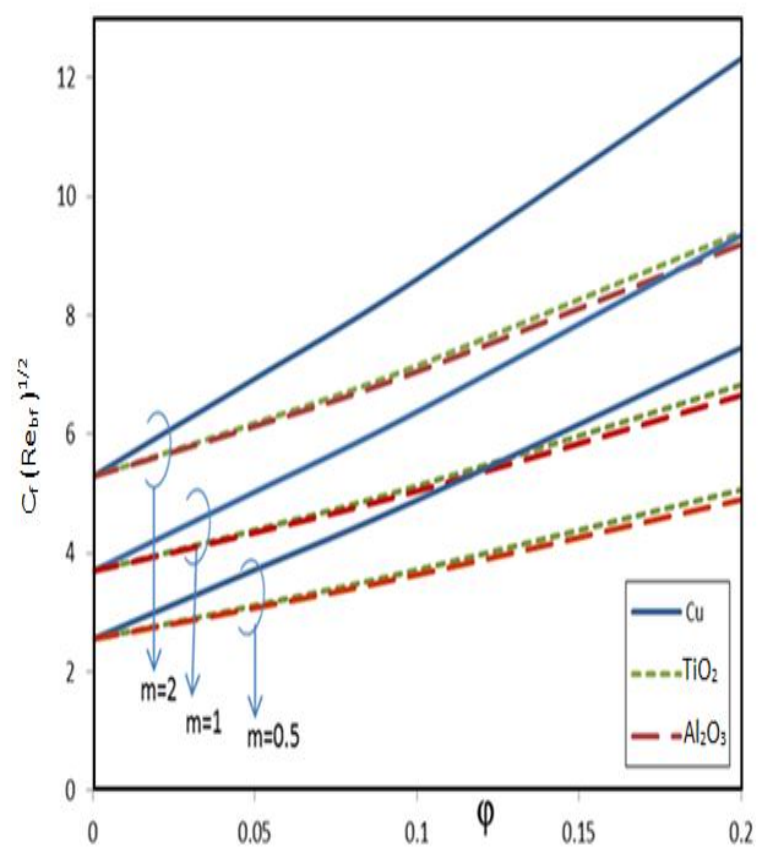

Figure 38. Skin-friction coefficient for water based nanofluid for different values of $m$.

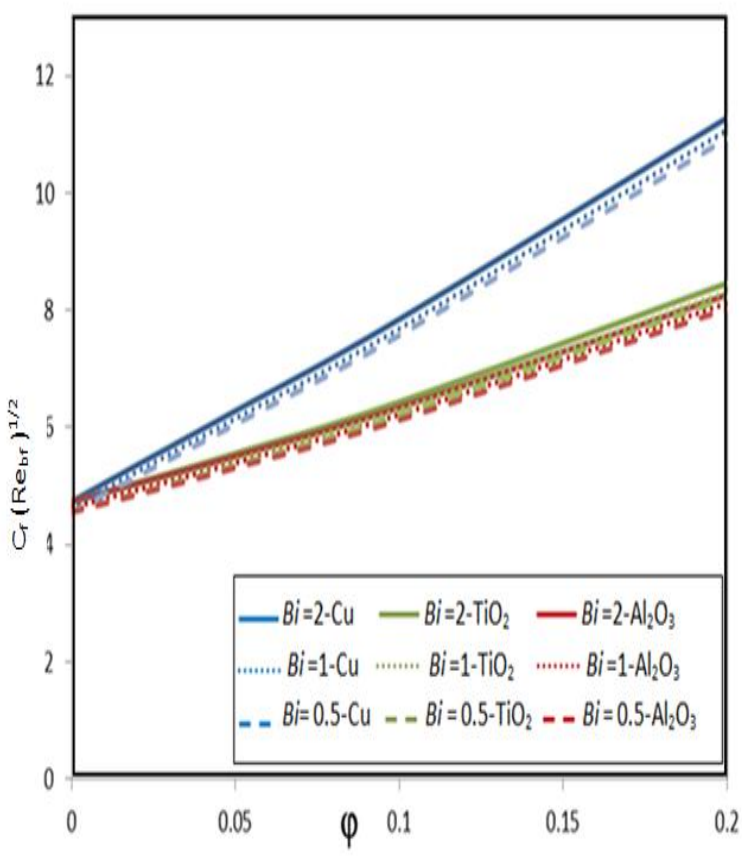

Figure 39. Skin-friction coefficient for water based nanofluids for different values of $B i$.

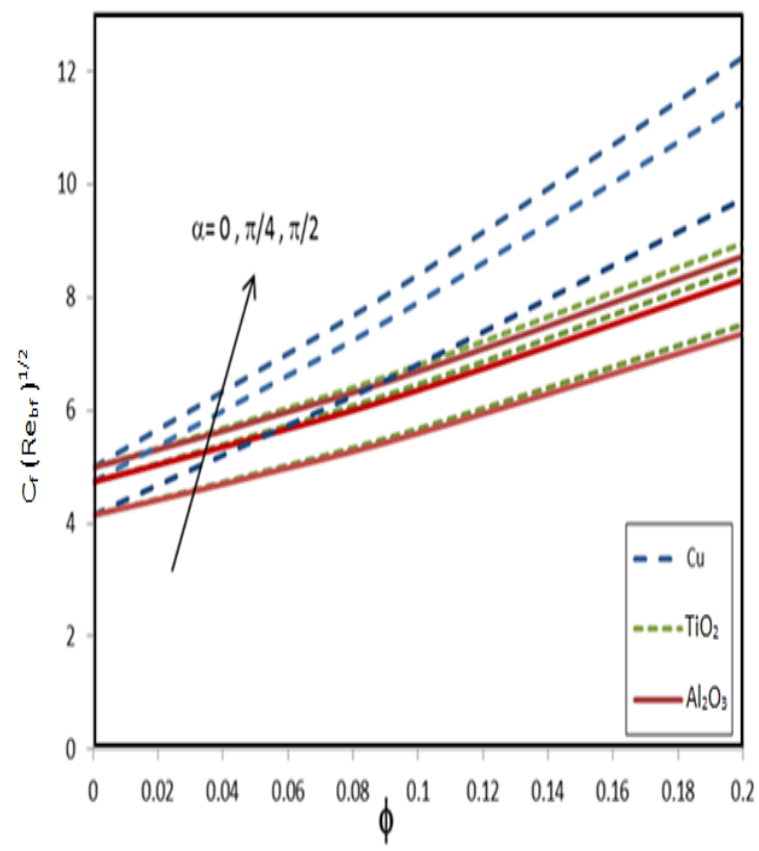

Figure 40. Skin-friction coefficient for water based nanofluid for different values of $\alpha$.

\subsubsection{Skin-friction coefficient}

\subsubsection{Skin-friction coefficient for different base fluids with $\mathrm{Cu}$ nanoparticles}

The variation of the shear stress in terms of the skin-friction coefficient for different values of $\varphi, \alpha, m$, and $B i$ considering three different base fluids with $C u$ nanoparticles is shown in Figures 35 to 37, respectively. It is found that the skin-friction coefficient increases with the increase of the angle of inclination $\alpha$, as well as with the increase of the nanoparticle volume fraction, as can be seen from Figure 35. It is also found that the values of the skin-friction coefficient in $\mathrm{Cu}$ - $\mathrm{EO}$ nanofluid are higher than those of the other base fluids containing $\mathrm{Al}_{2} \mathrm{O}_{3}$ and $\mathrm{TiO}_{2}$ nanoparticles. It can be noticed from Figure 36 that the skin-friction coefficient increases with an increase in the stretching index $m$, irrespective of the choice of nanofluids. However, it is higher for $\mathrm{Cu}-\mathrm{EO}$ nanofluids, which means that the base fluids 
are very important in the cooling and heating processes. The effect of $B i$ on the skin-friction coefficients is very similar to those of $\alpha$ and $m$, as can be found from Figure 37 .

\subsubsection{Skin-friction coefficient for water-based nanofluids}

Figures 38 to 40 respectively display the behavior of the skin-friction coefficient under the effects of stretching parameter $m$, Biot number $B i$, and angle of inclination $\alpha$, using water-based nanofluids having different nanoparticles. From these figures we see that the skin-friction coefficients for $\mathrm{Cu}-\mathrm{H}_{2} \mathrm{O}$ nanofluids are higher than the values corresponding to those of $\mathrm{TiO}_{2}-\mathrm{H}_{2} \mathrm{O}$ and $\mathrm{Al}_{2} \mathrm{O}_{3}-\mathrm{H}_{2} \mathrm{O}$ nanofluids for all values of the stretching index $m, B i$, and $\alpha$.

\section{Conclusions}

In this paper we have studied numerically the convective heat transfer mechanism of nanofluids over a nonlinear inclined stretching surface using the three different base fluids, water, ethylene glycol, and engine oil, and considering three different nanoparticles, $\mathrm{Cu}, \mathrm{Al}_{2} \mathrm{O}_{3}$ and $\mathrm{TiO}_{2}$. A magnetic field of uniform strength was applied along the normal direction of the flow. The lower surface of the sheet was heated by a convection current of a hot fluid different from the studied nanofluids. Various shapes (cylindrical, spherical and arbitrary) of the nanoparticles were also considered to investigate their influences on the flow and temperature fields.

Following our numerical computations it is concluded that addition of nanoparticles to the base fluid may not always increase the rate of heat transfer; it is significantly controlled by the surface convective parameter. The type of nanofluid is a key factor for heat transfer enhancement. Nanofluid velocity increases with an increase of the inclination angle parameter, thermal buoyancy parameter, nanoparticle volume fraction and nonlinear stretching index. Nanofluid velocity decreases with the increase of the Hartmann number. The velocity of the nanofluid is higher than the velocity of the base fluid. The velocity of the ethylene glycol- $\mathrm{Al}_{2} \mathrm{O}_{3}$ nanofluid has the lowest value for velocity, while water$\mathrm{Al}_{2} \mathrm{O}_{3}$ nanofluid has the highest value for velocity followed by engine oil- $\mathrm{Al}_{2} \mathrm{O}_{3}$. The temperature of a nanofluid increases with the increase of the angle of inclination, Hartmann number, nanoparticle volume fraction parameter, thermal buoyancy parameter and Biot number. The temperature of a nanofluid decreases with the increase of the nonlinear stretching index and empirical shape factor. The temperature in the engine oil-based nanofluid is higher than the temperature in the water and ethylene glycol-based nanofluids. A nanofluid with $\mathrm{Cu}$ nanoparticles has a higher temperature than nanofluids containing $\mathrm{Al}_{2} \mathrm{O}_{3}$ nanoparticles. The rate of heat transfer decreases with the increase of the stretching index, except in the water-based nanofluids. The rate of heat transfer in $\mathrm{TiO}_{2}$-water nanofluid is higher than the rate of heat transfer in $\mathrm{Cu}$-water and $\mathrm{Al}_{2} \mathrm{O}_{3}$-water nanofluids. Shear stress increases significantly with the increase of the inclination angle of the surface. Shear stress in the engine oil-based nanofluid is higher than the shear stress in the water- and ethylene glycol-based nanofluids.

\section{Acknowledgement}

This research work was supported by the grant IG/SCI/DOMS/13/05, College of Science, Sultan Qaboos University. We also express our gratitude to the anonymous referees for their valuable comments and suggestions.

\section{References}

1. Choi, S.U.S. and Eastman, J.A. Enhancing thermal conductivity of fluids with nanoparticles. Proc. ASME, November 12-17, 1995, San Francisco, CA.

2. Kwak, K. and Kim, C. Viscosity and thermal conductivity of copper nanofluid dispersed in ethylene glycol. Korea-Australia Rheology J., 2005, 17, 35-40.

3. Tiwari, R.J., and Das. M.K. Heat transfer augmentation in a two-sided lid-driven differentially heated square cavity utilizing nanofluids. Int. J. Heat Mass Transfer, 2007, 50, 2002-2018.

4. Kakac, S. and Pramuanjaroenkij. Review of convective heat transfer enhancement with nanofluids. Int. J. Heat Mass Transfer, 2009, 52, 3187-3196.

5. Khanafer, K., Vafai, K. and Lightstone, M. Buoyancy driven heat transfer enhancement in a two dimensional enclosure utilizing nanofluids. Int. J. Heat Mass Transfer, 2003, 46, 3639-3653.

6. Wang, B., Zhou, L. and Peng, X. A fractal model for predicting the effective thermal conductivity of liquid with suspension of nanoparticles. Int. J. Heat Mass Transfer, 2003, 46, 2665-2672.

7. Das, S.K., Choi, S.U.S., Yu, W. and Pradeep, T. Nanofluids: Science and Technology, Wiley, New Jersey, 2008.

8. Choi, S.U.S. Enhancing thermal conductivity of fluids with nanoparticles, in: Proc. International Mechanical Engineering Congress and Exposition, San Francisco, USA. ASME, FED 231/MD, 1995, Vol. 66, pp. 99105.

9. Nield, D.A. and Bejan, A. Convection in Porous Media ( $4^{\text {th }}$ edition), Springer,New York, 2013. 
10. Buongiorno, J. Convective transport in nanofluids. ASME J. Heat Transfer, 2006, 128, 240-250.

11. Wong, K.F.V. and Leon, O.D. Applications of nanofluids: current and future, Adv. Mech. Eng., 2010, 519659 (11pages).

12. Lee, J.H., Lee, S.H., Choi, C.J., Jang, S.P. and Choi, S.U.S. A review of thermal conductivity data, mechanics and models for nanofluids. Int. J. Micro-Nano Scale Transport, 2010, 1, 269-322.

13. Eagen, J., Rusconi, R., Piazz, R. and Yip, S. The classical nature of thermal conduction in nanofluids. ASME J. Heat Transfer., 2011, 132,102402 (14 pages).

14. Fan, J. and Wang, L. Review of heat conduction in nanofluids. ASME J. Heat Transfer., 2011, 133, 040801 (14 pages).

15. Mahian, O., Kianifar, A., Kalogirou, S.A., Pop, I. and Wonhwises, S. A review of the applications of nanofluids in solar energy. Int. J. Heat Mass Transfer, 2013, 57, 582-594.

16. Abu-nada, E. Application of nanofluids for heat transfer enhancement of separated flows encountered in a backward facing step. Int. J. Heat Fluid Flow, 2008, 29, 242-249.

17. Oztop, H.F. and Abu-nada, E. Numerical study of natural convection in partially heated rectangular enclosures filled with nanofluids. Int. J. Heat Fluid Flow, 2008, 29,1326-1336.

18. Nield, D.A. and Kuznetsov, A.V. The Cheng-Minkowycz problem for natural convective boundary-layer flow in a porous medium saturated by a nanofluid. Int. J. Heat Mass Transfer, 2009, 52, 5792-5795.

19. Abu-nada, E. and Oztop, H.F. Effects of inclination angle on natural convection in enclosures filled with $\mathrm{Cu}-$ water nanofluid. Int. J. Heat Fluid Flow, 2009, 30, 669-678.

20. Congedo, P.M., Collura, S. and Congedo, P.M. Modeling and analysis of natural convection heat transfer in nanofluids. In: Proc. ASME "Summer Heat Transfer Conference”, 2009, 3, 569-579.

21. Kuznetsov, A.V. and Nield, D.A. Natural convective boundary-layer flow of a nanofluid past a vertical plate. Int. J. Thermal Sciences, 2010, 49, 243-247.

22. Kuznetsov, A.V. and Nield, D.A. The Cheng-Minkowycz problem for natural convective boundary layer flow in a porous medium saturated by a nanofluid: A revised model, Int. J. Heat Mass Transfer, 2013, 65, 682685.

23. Muthtamilsevan, M., Kandaswamy, P., and Lee, J. Heat transfer enhancement of copper-water nanofluids in a lid driven enclosure. Commun. Nonlin. Sci. Numer. Simulat., 2010, 15, 1501-1510.

24. Bachok, N., Ishak, A. and Pop, I. Boundary-layer flow of nanofluids over a moving surface in a flowing fluid. Int. J. Thermal Sciences, 2010, 49, 1663-1668.

25. Ahmed, S. and Pop, I. Mixed convection boundary layer flow from a vertical flat plate embedded in a porous medium filled with nanofluids. Int. Commun. Heat Mass Transfer, 2010, 37, 987-991.

26. Khan, W.A. and Pop, I. Boundary-layer flow of a nanofluid past a stretching sheet. Int. J. Heat Mass Transfer, 2010, 53, 2477-2483.

27. Beg, O.A., Ghosh, S.K. and Beg, T.A. Applied magnetofluid dynamics: modelling and computation. Lambert Academic, Germany, 2011.

28. Gorla, R.S.R. and Chamkha, A. Natural convective boundary layer flow over a horizontal plate embedded in a porous medium saturated with a nanofluid. J. Mod. Phys., 2011, 2, 62-71.

29. Gorla, R.S.R., EL-Kabeir, S.M.M. and Rashad, A.M. Heat transfer in the boundary layer on a stretching circular cylinder in a nanofluid. AIAA J. Thermophy. Heat Transfer, 2011, 25, 183-186.

30. Rashidi, M.M., Beg, O.A., Asadi, M. and Rastegari, M.T. DTM-Padé modeling of natural convective boundary layer flow of a nanofluid past a vertical surface. Int. J. Thermal Environ. Eng., 2011, 4(1), 13-24.

31. Rahman, M.M. and Aziz, A. Heat transfer in water based nanofluids $\left(\mathrm{TiO}_{2}-\mathrm{H}_{2} \mathrm{O}, \mathrm{Al}_{2} \mathrm{O}_{3}-\mathrm{H}_{2} \mathrm{O}\right.$ and $\left.\mathrm{Cu}-\mathrm{H}_{2} \mathrm{O}\right)$ over a stretching cylinder. Int. J. Heat Tech., 2012, 30(2), 43-49.

32. Rahman, M.M., AL-Lawatia, M.A., Eltayeb, I.A., and AL-Salti, N. Hydromagnetic slip flow of water based nanofluids past a wedge with convective surface in the presence of heat generation (or) absorption. Int. J. Thermal Sci., 2012, 57, 172-182.

33. Rahman, M.M. and Eltayeb, I.A. Radiative heat transfer in a hydromagnetic nanofluid past a non-linear stretching surface with convective boundary condition. Meccanica, 2013, 48, 601-615.

34. Rahman, M.M., Rosca, A.V. and Pop, I. Boundary layer flow of a nanofluid past a permeable exponentially shrinking surface with second order slip using Buongiorno's model. Int. J. Heat Mass Transfer, 2014, 77, 1133-1143.

35. Rahman, M.M., Rosca, A.V. and Pop, I. Boundary layer flow of a nanofluid past a permeable exponentially shrinking surface with convective boundary condition using Buongiorno's model, Int. J. Numer. Methods Heat Fluid Flow (accepted for publication), 2014, 25(2).

36. Rahman, M.M., AL-Marzoui, W.A., AL-Hatmi, F.S., AL-Lawatia, M.A. and Eltayeb, I.A. The role of a convective surface in models of the radiative heat transfer in nanofluids. Nuclear Eng. Design, 2014, 275, 282-392.

37. Crane, L.J. Flow past a stretching plate. J. App. Math. Phys. (ZAMP), 1970, 21, 645-647.

38. Nadeem, S. and Lee, C. Boundary layer flow of nanofluid over an exponentially stretching surface. Nanoscale Res. Lett., 2012, 7, 94 (6 pages). 
39. Yao, S., Fang, T. and Zhong, Y. Heat transfer of a generalized stretching/shrinking wall problem with convective boundary conditions. Commun. Nonlin. Sci. Numer. Simulat., 2011, 16, 752-760.

40. Hamad, M.A.A. and Pop, I. Scaling transformations for boundary layer flow near the stagnation-point on a heated permeable stretching surface in a porous medium saturated with a nanofluid and heat generation/absorption effects. Transp. Porous Media, 2011, 87, 25-39.

41. Brinkman, H.C. The viscosity of concentrated suspensions and solutions. J. Chem. Phys, 1952, 20, 571-581.

42. Xuan, Y. and Li. Y.Q. Investigation on convective heat transfer and flow features of nanofluids. ASME $J$. Heat Transfer, 2003, 151-155.

43. Mansour, M.A. and Ahmed, S.A. Mixed convection flows in a square lid-driven cavity with heat source at the bottom utilizing nanofluid. Can. J. Chem. Eng., 2012, 90, 100-110.

44. Rana, P. and Bhargava, R. Numerical study of heat transfer enhancement in mixed convection flow along a vertical plate with heat source/sink utilizing nanofluids. Commun. Nonlin. Sci. Numer. Simulat., 2011, 16, 4318-4334.

45. AL-Hatmi, M.M. Convective heat transfer in nanofluid. M.Sc. Thesis, Sultan Qaboos University, Sultanate of Oman, 2014.

46. Yacob, N.A., Ishak, A. and Pop, I. Falkner-Skan problem for a static or moving wedge in nanofluids. Int. J. Thermal Sci., 2011, 50, 133-139.

Received 14 September 2014

Accepted 13 November 2014 